\title{
Greenland ice sheet mass balance: distribution of increased mass loss with climate warming; 2003-07 versus 1992-2002
}

\author{
H. Jay ZWALLY, Jun LI, Anita C. BRENNER, Matthew BECKLEY, Helen G. CORNEJO, \\ John DiMARZIO, Mario B. GIOVINETTO, Thomas A. NEUMANN, John ROBBINS, \\ Jack L. SABA, Donghui YI, Weili WANG \\ NASA Goddard Space Flight Center, Code 614.1, Greenbelt, Maryland 20771, USA \\ E-mail: zwally@icesat2.gsfc.nasa.gov
}

\begin{abstract}
We derive mass changes of the Greenland ice sheet (GIS) for 2003-07 from ICESat laser altimetry and compare them with results for 1992-2002 from ERS radar and airborne laser altimetry. The GIS continued to grow inland and thin at the margins during 2003-07, but surface melting and accelerated flow significantly increased the marginal thinning compared with the 1990s. The net balance changed from a small loss of $7 \pm 3 \mathrm{Gta}^{-1}$ in the 1990 s to $171 \pm 4 \mathrm{Gta}^{-1}$ for 2003-07, contributing $0.5 \mathrm{~mm} \mathrm{a}^{-1}$ to recent global sea-level rise. We divide the derived mass changes into two components: (1) from changes in melting and ice dynamics and (2) from changes in precipitation and accumulation rate. We use our firn compaction model to calculate the elevation changes driven by changes in both temperature and accumulation rate and to calculate the appropriate density to convert the accumulation-driven changes to mass changes. Increased losses from melting and ice dynamics $\left(17-206 \mathrm{Gt} \mathrm{a}^{-1}\right)$ are over seven times larger than increased gains from precipitation $\left(10-35 \mathrm{Gta}^{-1}\right)$ during a warming period of $\sim 2 \mathrm{~K}(10 \mathrm{a})^{-1}$ over the GIS. Above $2000 \mathrm{~m}$ elevation, the rate of gain decreased from 44 to $28 \mathrm{Gta}^{-1}$, while below $2000 \mathrm{~m}$ the rate of loss increased from 51 to $198 \mathrm{Gta}^{-1}$. Enhanced thinning below the equilibrium line on outlet glaciers indicates that increased melting has a significant impact on outlet glaciers, as well as accelerating ice flow. Increased thinning at higher elevations appears to be induced by dynamic coupling to thinning at the margins on decadal timescales.
\end{abstract}

\section{INTRODUCTION}

Mass changes in the Greenland ice sheet (GIS) are of considerable interest because of their sensitivity to climate change, the mass-loss contribution to sea-level rise, and the likelihood of an increasing rate of mass loss with climate warming. In recent years, the GIS has experienced increased surface melting from increasing temperatures (Hall and others, 2008; Box and others, 2009), increased snow accumulation from increasing precipitation (Box and others, 2006; Hanna and others, 2008), accelerated ice flow from melt/acceleration effects (Zwally and others, 2002b; Joughin and others, 2008b; Van de Wal and others, 2008; Bartholomew and others, 2010) and increased discharge from accelerating outlet glaciers due to warming ocean waters (Holland and others, 2008; Straneo and others, 2010). In response, the GIS has been thinning at the margins and growing in its interior (Krabill and others, 2000; Johannessen and others, 2005; Zwally and others, 2005; Pritchard and others, 2009). The net rate of ice loss appears to have accelerated in recent years compared with the 1990s, but published values of the rate of mass loss and changes with time have differed widely (Alley and others, 2007; Shepherd and Wingham, 2007; AMAP, 2009).

Estimates of input and output (AMAP, 2009) for the GIS for a state of near balance give a mass gain of $550 \mathrm{Gta}^{-1}$ from precipitation (less evaporation), which is balanced by mass loss through meltwater and blowing snow $\left(370 \mathrm{Gta}^{-1}\right)$ and glacier discharge $\left(180 \mathrm{Gta}^{-1}\right)$. However, these values have large uncertainties and significant interannual variations. Variations in precipitation, temperature and other factors cause variations in the mass exchange at the surface and in the dynamics of ice flow toward the margins on land and through outlet glaciers into the ocean.

A review (Shepherd and Wingham, 2007) said 'it is reasonable ... to conclude the GIS is losing about $100 \mathrm{Gta}^{-1}$, which was consistent with the high-resolution analysis of Gravity Recovery and Climate Experiment (GRACE) data (Luthcke and others, 2006) that gave a net mass loss of $101 \mathrm{Gt} \mathrm{a}^{-1}$ for the period 2003-05. Furthermore, a $122 \pm 47 \mathrm{Gta}^{-1}$ increase in loss rate by 2005 compared with 1996 based on a mass flux analysis (Rignot and Kanagaratnam, 2006) is approximately consistent with the increase shown by the GRACE results for 2003-05 compared by Luthcke and others (2006) with the near balance for 1992-2002 from satellite-radar and airbornelaser altimetry (Zwally and others, 2005).

This paper focuses on the GIS mass balance for 2003-07 and the changes since 1992-2002, including the spatial distributions of mass balance and changes by drainage system and elevation. Our 2003-07 results are derived from the Ice, Cloud and land Elevation Satellite (ICESat)'s laser altimeter measurements (Zwally and others, 2002a) of surface elevations using some of the methodology previously applied (Zwally and others, 2005) to data from European Remote-sensing Satellite (ERS) radar altimetry and airborne laser altimetry (Airborne Topographic Mapper (ATM)). Significant improvements for determining mass changes, $\mathrm{d} M / \mathrm{d} t$, from elevation changes, $\mathrm{d} H / \mathrm{d} t$, for both the 1992-2002 and 2003-07 periods are (1) calculation of the appropriate densities to apply to changes in the thickness of the firn-ice column and (2) partitioning of $\mathrm{d} H / \mathrm{d} t$ and $\mathrm{d} M / \mathrm{d} t$ into components driven by accumulation variations and those driven by melting and ice dynamics. For 1992-2002, we use 


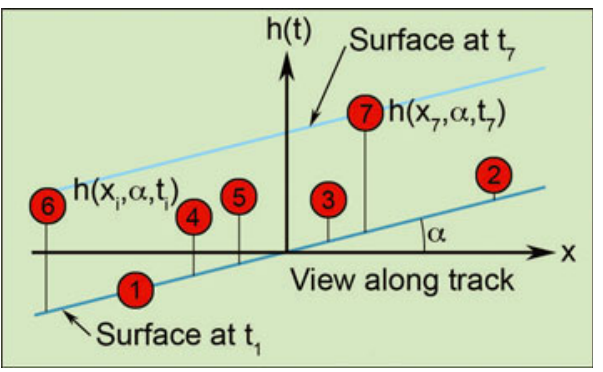

Fig. 1. Schematic of elevations $h\left(x_{i}, \alpha, t_{i}\right)$ for successive data collected on repeat tracks at times $t_{i}$ along an ICESat reference track with cross-track slope $\alpha$ and distance $x_{i}$ from the reference track. $h$ is shown increasing with time.

the previous $\mathrm{d} H / \mathrm{d} t$ (Zwally and others, 2005) calculated from elevation changes, $\mathrm{d} h / \mathrm{d} t$, calculated at crossovers where ERS satellite tracks cross on consecutive ascending and descending passes, with ATM data (Abdalati and others, 2001) added to fill in gridcells on outlet glaciers. For 2003-07, we calculate $\mathrm{d} H / \mathrm{d} t$ from $\mathrm{d} h / \mathrm{d} t$ calculated from ICESat data collected on successive satellite passes along closely spaced ground tracks ('repeat tracks'), which significantly increases the along-track spatial resolution and the density of derived $\mathrm{d} h / \mathrm{d} t$ compared with crossover analysis.

\section{ELEVATION CHANGE, $d h / d t$, FROM REPEAT- TRACK ANALYSIS OF ICESAT DATA}

Our repeat-track analysis to derive $\mathrm{d} h / \mathrm{d} t$ from ICESat data is enabled by ICESat's capability to point the laser beam to reference tracks over the ice sheets to $\pm 100 \mathrm{~m}(1 \sigma)$. However, because the tracks do not repeat exactly, the surface elevation, $h\left(x, y, t_{i}\right)$, measured along a repeat pass $(y$ direction) at time $t_{i}$ depends on the cross-track surface slope, $\alpha$, and the cross-track distance, $x$, as well as actual elevation changes with time. This mixing of apparent height changes caused by cross-track displacements and real height changes, $h\left(t_{i}\right)$, is illustrated in Figure 1 and by

$$
h\left(x, y_{r}, \alpha, t_{i}\right)=x \tan \alpha+t_{i}\left(\frac{\mathrm{d} h}{\mathrm{~d} t}\right)+h_{0}\left(y_{r}, t_{0}\right),
$$

where $h_{0}$ is the elevation at the position, $y_{r}$, of the reference track at $t_{0}$. Use of Equation (1) assumes the cross-track surface slope is constant over distances of $\sim 200 \mathrm{~m}$ and that $\mathrm{d} h / \mathrm{d} t$ is constant with time, i.e. $h(t)$ changes are linear. Although important seasonal and interannual variations in $h(x, y, \alpha, t)$ are ignored in this solution, departures from linearity are nevertheless retained in the height residuals relative to the linear solution and can be further analyzed. Measured $h(x, y, \alpha, t)$ are first interpolated to equally spaced $(172 \mathrm{~m})$ reference points along each track. We then solve Equation (1) by least-squares methods for three parameters, $\alpha, \mathrm{d} h / \mathrm{d} t, h_{0}$, at each reference point, which requires data on at least $N=4$ along-track repeats. For solutions with $N=10$ repeats, for example, we obtain an accuracy, $\sigma_{\mathrm{d} h / \mathrm{d} t}$ for $\mathrm{d} h / \mathrm{d} t$ of better than $25 \mathrm{~cm} \mathrm{a}^{-1}$ for $\alpha<2^{\circ}$ at one-point along-track solutions (Fig. 2a). The resulting standard errors, $\sigma_{\mathrm{d} H / \mathrm{d} t}$ and $\sigma_{\alpha}$, on $\mathrm{d} h / \mathrm{d} t$ and $\alpha$ decrease with increasing $N$ by $1 /(N-3)^{1 / 2}$ as expected. We use data from 12 laser campaigns (also designated as Laser 2a, 2b, 2c, 3a, 3b, 3c, 3d, 3e, 3f, 3g, 3h and 3 i) from the fall of 2003 to the fall of 2007, i.e. F03, W04, S04, F04, W05, S05, F05, W06, S06, F06, W07 and F07, where $F$ indicates boreal fall, $W$ indicates boreal winter, S indicates boreal spring and 03 indicates 2003, etc. The effective length of each campaign was 33 to $\sim 36$ days. (F03 was 45 days, but the additional ground tracks were not covered in subsequent campaigns.) However, data are not continuous along each track due to losses in thick-cloud cover, so $N$ varies with location from a maximum of 12 . The data versions are all release 428, except for S04, which is release 128. Data can be obtained from NASA's archive at the US National Snow and Ice Data Center (http://nsidc.org/ data/icesat/index.html).

The $\mathrm{d} h / \mathrm{d} t$ results are improved by a seven-point solution that uses data at three points on either side of each reference point, i.e. strips that are $\sim 1 \mathrm{~km}$ along track, and a quadratic surface in the along-track $y$ direction that is derived from multiple repeats. The maximum number of $h(x, y, \alpha, t)$ values used in the seven-point solutions is 84 . We obtain seven-point solutions at $97 \%$ of the locations. For the other 3\%, which are mostly near the edge of the ice sheet where a satisfactory seven-point solution cannot be obtained, we use one-point solutions. The formal $\sigma_{\mathrm{d} h / \mathrm{d} t}$ on $\mathrm{d} h / \mathrm{d} t$ from the seven-point solutions are multiplied by $\sqrt{7}$ to account for the non-independence of consecutive alongtrack solutions.
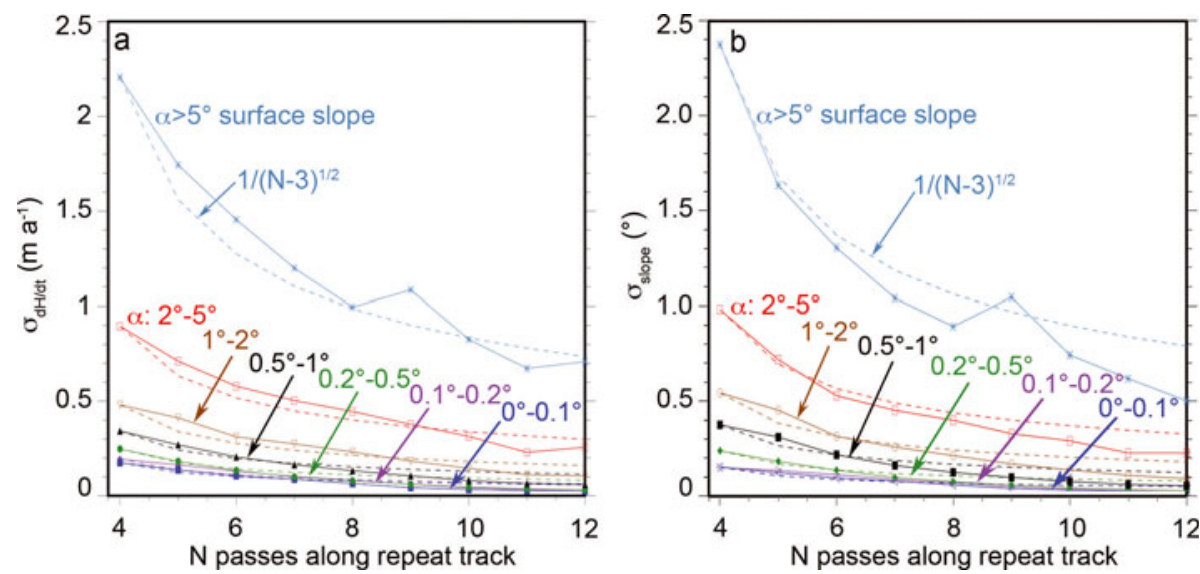

Fig. 2. (a) Error on ICESat $\mathrm{d} h / \mathrm{d} t\left(\mathrm{~m} \mathrm{a}^{-1}\right)$ as a function of the number of repeats, $N$, used in the solution at each along-track location separated by $172 \mathrm{~m} .0 .25 \mathrm{~m} \mathrm{a}^{-1}$ accuracy is achieved for $N \geq 10$ repeats for slopes $<2^{\circ}$. Dashed curves are $1 /(N-3)^{1 / 2}$ fits to the errors. (b) Error on slope $\alpha$ as a function of $N$. Slope error is about $\pm 20 \%$ for $N=10$. 

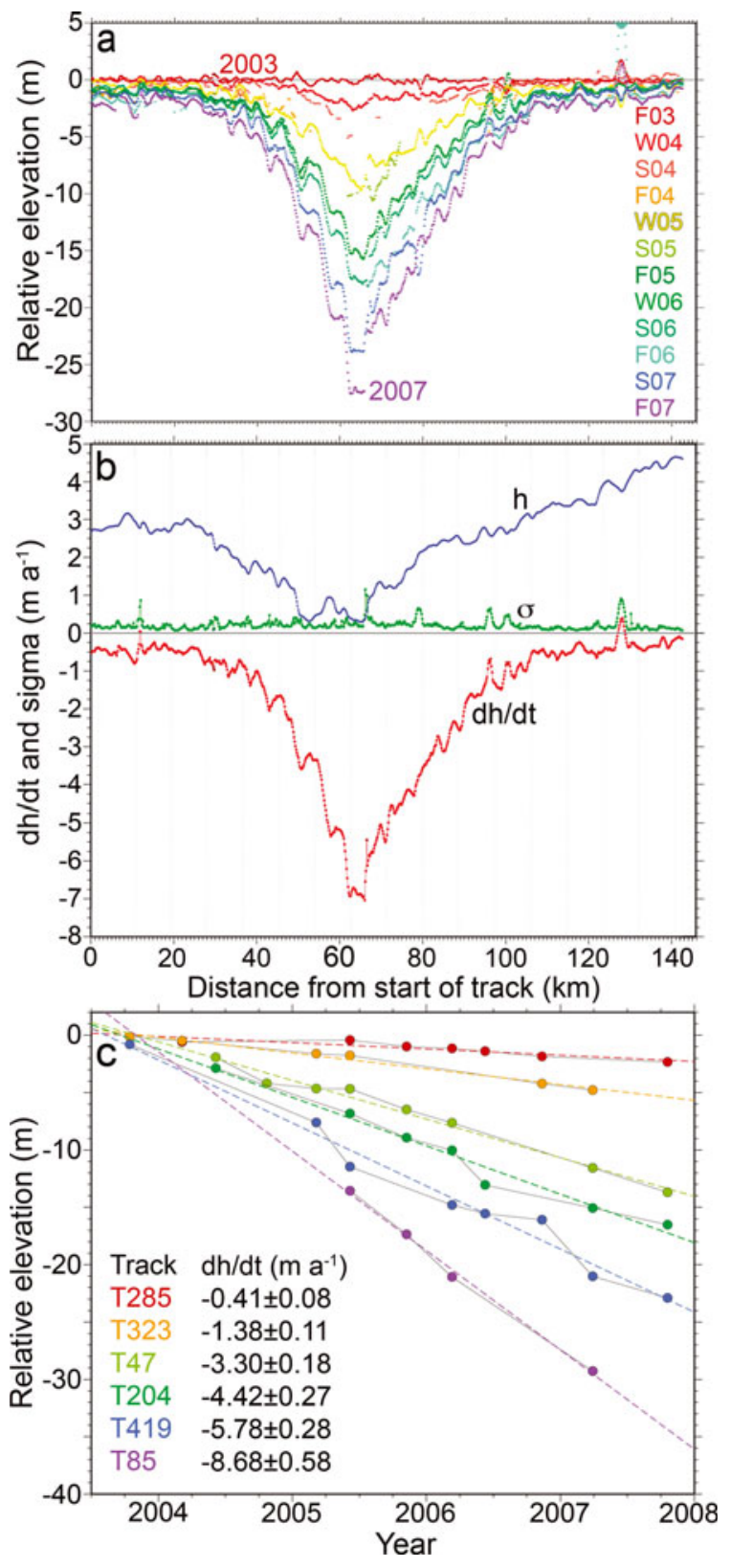

Fig. 3. (a) ICESat surface elevation ( $h$ ) profiles (ten-point smoothing) relative to the first profile from fall 2003 across Jakobshavn Isbræ along T419 (Fig. 14). Maximum surface lowering is $27.6 \mathrm{~m}$ in 4 years. F03 is fall 2003, W04 is winter 2004, S04 is spring 2004, etc. (b) Profiles of $h$ from 1030 to $1465 \mathrm{~m}$, derived $\mathrm{d} h / \mathrm{d} t$, and $\sigma_{\mathrm{d} h / \mathrm{d} t}$ from along-track solutions at $172 \mathrm{~m}$ spacing. Units of $h$ are from $1000 \mathrm{~m}$ ( 0 on $y$-axis) to $1500 \mathrm{~m}$ ( 5 on $y$-axis). Maximum $\mathrm{d} h / \mathrm{d} t$ is $7 \mathrm{~m} \mathrm{a}^{-1}$ near the center of the glacier. Matching peaks in $h$ and $\mathrm{d} h / \mathrm{d} t$ indicate oscillations are growing with time. (c) $h(t)$ at crossings of ICESat tracks with a flowline near the center of the glacier (Fig. 14). Over 4 years, $h(t)$ is close to linear.

We further improve the relative accuracy to the $\mathrm{cm}$ level for each of the 12 campaigns by referencing to the ocean surface, i.e. the open water within sea ice, on the Arctic Ocean. This reduces inter-campaign range biases. We empirically determine an elevation correction, $d$, from the time variation of the average mean sea surface over the Arctic Ocean using the methods described by Zwally and others (2008). Although the magnitude of $d$ is spatially variable, its time variation appears to be the same over the Arctic Ocean, so we take it to be applicable to Greenland as well. The respective values of $d$ for the 12 periods are
$-0.049,0.045,0.132,-0.061,-0.104,0.021,0.011,0.014$, $0.012,0.074,0.004$ and $0.043 \mathrm{~m}$. We reduce the time variation of these $d$ values by $0.003 \mathrm{~m} \mathrm{a}^{-1}$ to account for the current rate of sea-level rise, and then subtract the reduced $d$ values from the measured elevations. The linear trend in the reduced $d$ is $0.006 \mathrm{ma}^{-1}$, which averaged over all of Greenland increases the overall mass loss by $\sim 9 \mathrm{Gta}^{-1}$ compared with data without the $d$ correction applied.

\subsection{Characteristics of $\mathrm{d} h / \mathrm{d} \boldsymbol{t}$ on Jakobshavn Isbræ}

We select Jakobshavn Isbræ, west-central Greenland, to show the characteristics of the $d h / d t$ derived from ICESatmeasured surface elevations, $h$, in Figure $3 a$, including the small $\sigma_{\mathrm{d} h / \mathrm{d} t}$ relative to $\mathrm{d} h / \mathrm{d} t$, the details of the oscillations in the $h$ and $\mathrm{d} h / \mathrm{d} t$ profiles, the consistency of the oscillations on consecutive profiles, and the small variation from linearity in the $h(t)$ at different locations. Jakobshavn is of particular interest because of its rapid speed-up and increased thinning rate inland of the grounding line as the floating ice tongue thinned and broke away during 19962004 (Joughin and others, 2008a; Thomas and others, 2009). Profiles of $h$ for 12 ICESat repeats along track 419 (T419) relative to the first pass in fall 2003 are shown in Figure 3a

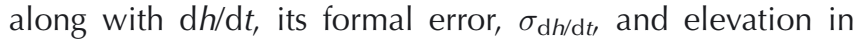
Figure $3 b$ (track locations are shown in Fig. 14 further below).

The largest $\mathrm{d} h / \mathrm{dt}$ derived in this region is $11.3 \mathrm{~m} \mathrm{a}^{-1}$ at the end $\left(69.17^{\circ} \mathrm{N}, 49.32^{\circ} \mathrm{W}\right)$ of the discontinuous T85, near the center of the glacier downstream from T419. The linear character of $h(t)$ in Figure 3c at six crossings of ICESat tracks with a flowline down the center of the glacier (Fig. 14), where $\mathrm{d} h / \mathrm{d} t$ values range from -8.7 to $-0.1 \mathrm{~m} \mathrm{a}^{-1}$ below and above the $E L$, shows that the glacier's thinning rate is nearly constant during 2003-07. Therefore, any residual effects from removal of the ice tongue do not appear to be causing either a significant increase or decrease in the thinning rate in this portion of the glacier.

\section{MAPPING OF $\mathrm{d} H / \mathrm{d} t$}

We average the derived ICESat $\mathrm{d} h / \mathrm{d} t$ values over $\sim 50 \mathrm{~km}$ gridcells to obtain the average elevation change, $\mathrm{d} H / \mathrm{d} t$, in

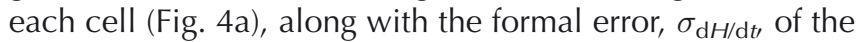
average $\mathrm{d} H / \mathrm{d} t$ (Fig. 5a). The $\mathrm{d} H / \mathrm{d} t$ values in Figure $4 \mathrm{a}$ are similar to the map of along-track $\mathrm{d} h / \mathrm{d} t$ derived from ICESat data as shown in figure 2 of Pritchard and others (2009), which described the patterns of dynamic thinning but did not calculate $\mathrm{d} M / \mathrm{d} t$, as we do in section 4 . The ICESat $\sigma_{\mathrm{d} H / \mathrm{d} t}$ are approximately one-third of the corresponding values of those for ERS radar altimetry (Fig. 5b), which are computed from the time-series analysis of crossover differences (Zwally and others, 2005). The smaller $\sigma_{\mathrm{d} H / \mathrm{d} t}$ for ICESat reflects the higher accuracy of the laser versus radar altimetry and possibly the higher accuracy of the repeat-track analysis (even though data collection was not continuous).

The $\mathrm{d} M / \mathrm{d} t$, area and other parameter calculations in the following sections are made using the $50 \mathrm{~km}$ gridcell averages. However, at the edges of the ice sheet, the $50 \mathrm{~km}$ gridcells are split into portions lying on and off the ice sheet, using an ice-sheet boundary with $1-2 \mathrm{~km}$ resolution. For the $\mathrm{d} H / \mathrm{d} t$ from ICESat data, only $\mathrm{d} h / \mathrm{d} t$ data within the portion of the cells lying on the ice sheet are used in the calculations. For the $\mathrm{d} H / \mathrm{d} t$ from ERS/ATM, the procedures for selection of crossovers, the use of ATM data, and optimal 


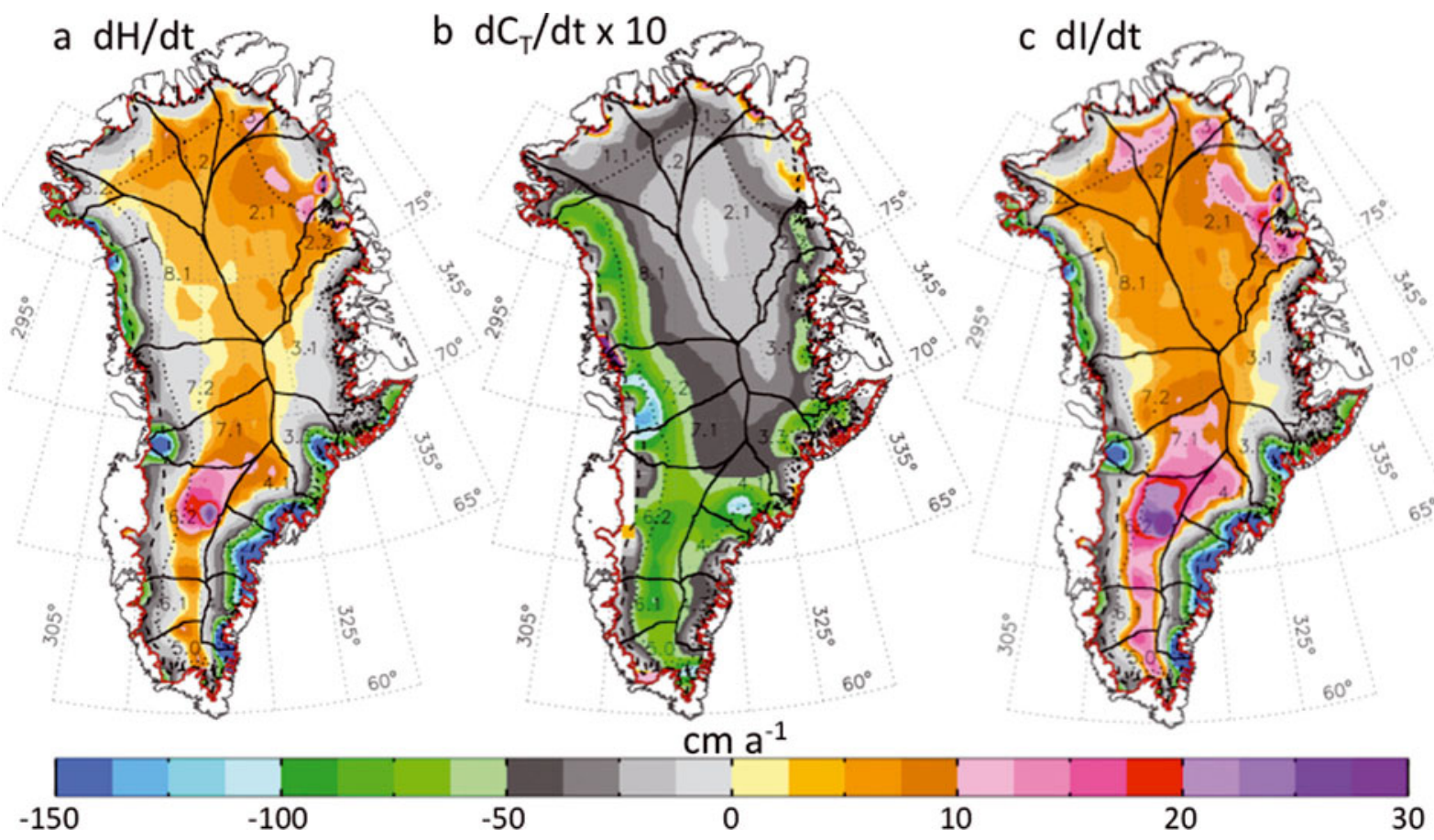

Fig. 4. (a) ICESat $\mathrm{d} H / \mathrm{d} t=\langle\mathrm{dh} / \mathrm{d} t\rangle$ averaged in $\sim 50 \mathrm{~km}$ gridcells. (b) Temperature-driven part of the firn compaction $\mathrm{d} C_{T} / \mathrm{d} t$ times 10 . (c) $\mathrm{d} / / \mathrm{d} t=(\mathrm{d} H / \mathrm{d} t)-\left(\mathrm{d} C_{T} / \mathrm{d} t\right)-(\mathrm{d} B / \mathrm{d} t)$. Although $\mathrm{d} C_{T} / \mathrm{d} t$ is generally smaller than $\mathrm{d} H / \mathrm{d} t$, it shifts the $\mathrm{d} H / \mathrm{d} t=0$ line by $\sim 100 \mathrm{~km}$ in the northwest as shown by the arrows. In addition to the delineation of the drainage systems (black curves), the $2000 \mathrm{~m}$ contour (dotted curve), the EL (dashed curve) and the ice-sheet boundary (red curve) are shown here and in Figures 5-9.

interpolation to fill in missing cells were given by Zwally and others (2005); here we also weight all the boundary cells by the fraction of the cell area lying within the boundary. An important correction to $\mathrm{d} H / \mathrm{d} t$ from radar altimetry is the backscatter correction previously applied (Zwally and others, 2005), which empirically corrects for variations in the effective backscattering depth in the firn and is similar to that applied by Davis and others (2005) and Wingham and others (2006).

\section{DERIVATION OF ICE-MASS CHANGES, $\mathrm{d} M / \mathrm{d} t$, FROM ELEVATION CHANGES, $\mathrm{d} H / \mathrm{d} t$}

Derivation of $\mathrm{d} M / \mathrm{d} t$ from $\mathrm{d} H / \mathrm{d} t$ requires consideration (Zwally and Li, 2002) of the surface mass balance, firn compaction, dynamics, and underlying bedrock motion:

$$
\frac{\mathrm{d} H(t)}{\mathrm{d} t}=\frac{A(t)}{\rho_{\mathrm{sf}}}-V_{\mathrm{fC}}(t)-\frac{A_{\mathrm{b}}(t)}{\rho_{\mathrm{i}}}-V_{\mathrm{ice}}+\frac{\mathrm{d} B}{\mathrm{~d} t},
$$

where $A(t)$ is the snow accumulation rate, $\rho_{\text {sf }}$ is the density of near-surface firn (typically 0.33$), V_{\mathrm{fc}}(t)$ is the velocity of firn compaction at the surface, $A_{\mathrm{b}}(t)$ is the ablation rate, $\rho_{\mathrm{i}}=0.90$ is the density of glacier ice, $V_{\text {ice }}$ is the vertical velocity of the ice at the firn/ice transition, and $\mathrm{d} B / \mathrm{d} t$ is the vertical bedrock motion. In steady state with a long-term average accumulation rate of $\langle A\rangle, V_{\text {ice }}=\langle A\rangle / \rho_{\mathrm{i}}$ in the accumulation zone and $V_{\mathrm{fC}}=1.7 V_{\text {ice }}$ using $\rho_{\mathrm{sf}}=0.33$ and $\rho_{\mathrm{i}}=0.90$. The units of $A(t)$ and $A_{\mathrm{b}}(t)$ are cmw.e. $\mathrm{a}^{-1}$, the units of velocities and elevation changes are $\mathrm{cm} \mathrm{a}^{-1}$, and all densities are relative to $\rho_{\text {water }}=1 . H, A$ and $\mathrm{d} B / \mathrm{d} t$ are positive upward and $V_{\mathrm{fc}}, A_{\mathrm{b}}$ and $V_{\text {ice }}$ are positive downward as commonly defined for these parameters.

For non-steady state, we rewrite the ice-sheet terms in Equation (2) as perturbations from steady state, assuming that $\mathrm{d} B / \mathrm{d} t$ is constant during the time of the measurements:

$$
\frac{\mathrm{d} H}{\mathrm{~d} t}=\frac{\mathrm{d} H^{\mathrm{a}}}{\mathrm{d} t}+\frac{\mathrm{d} C_{A T}}{\mathrm{~d} t}+\frac{\mathrm{d} H_{\mathrm{b}}}{\mathrm{d} t}+\frac{\mathrm{d} H_{\mathrm{d}}}{\mathrm{d} t}+\frac{\mathrm{d} B}{\mathrm{~d} t}
$$

where $\mathrm{d} H^{\mathrm{a}} / \mathrm{d} t=(A(t)-\langle A\rangle) / \rho_{\mathrm{sf}}$ is the direct change caused by $A(t), \mathrm{d} C_{A T} / \mathrm{d} t=-\left(V_{\mathrm{fC}}(t)-\left\langle V_{\mathrm{fC}}\right\rangle\right)$ is the change in firn-compaction rate driven by both $A(t)$ and temperature $T(t), \mathrm{d} H_{\mathrm{b}} / \mathrm{d} t=-$ $\left(A_{\mathrm{b}}(t)-\left\langle A_{\mathrm{b}}\right\rangle\right) / \rho_{\mathrm{i}}$ is driven by changes in the ablation rate, $\mathrm{d} H_{\mathrm{d}} /$ $\mathrm{d} t=-\left(V_{\text {ice }}(t)-\left\langle V_{\text {ice }}\right\rangle\right)$ is driven by dynamic changes in the ice flow relative to the long term, $\langle A\rangle$, and \langle\rangle indicates long-term averages of the various parameters. All terms in Equation (3) are positive upward and are defined as averages over some area, which in our following analyses are $50 \mathrm{~km}$ gridcells.

Positive values of $\mathrm{d} H_{\mathrm{d}} / \mathrm{d} t$ indicate that the ice flow is less than that required to balance the long-term average $\langle A\rangle$, which is described as dynamic thickening in the same manner as negative $\mathrm{d} H_{\mathrm{d}} / \mathrm{d} t$ is described as dynamic thinning. However, $\mathrm{d} H_{\mathrm{d}} / \mathrm{d} t$ includes not only long-term changes in the ice dynamics, but also short-term changes. For example, if $\mathrm{d} H_{\mathrm{d}} / \mathrm{d} t$ is determined during two different periods at an interval of 10 years, then both values of $\mathrm{d} H_{\mathrm{d}} / \mathrm{d} t$ would include multi-decadal dynamic imbalances compared with the multi-decadal average $\langle A\rangle$, and their difference would indicate the sub-decadal dynamic changes (see section 6.3).

\subsection{Separation of accumulation and temperature effects on firn compaction}

The firn-compaction $\left(\mathrm{d} C_{A T} / \mathrm{d} t\right)$ and $\mathrm{d} B / \mathrm{d} t$ terms in Equation (3) change $\mathrm{d} H / \mathrm{d} t$ but not $\mathrm{d} M / \mathrm{d} t$. Both $\mathrm{d} H^{\mathrm{a}} / \mathrm{d} t$ and $\mathrm{d} C_{A T} / \mathrm{d} t$ are affected by $A(t)$, and $\mathrm{d} C_{A T} / \mathrm{d} t$ depends strongly on $T(t)$ as previously used (Zwally and others, 2005) to calculate $d M /$ $\mathrm{d} t$. Importantly, $\mathrm{d} C_{A T} / \mathrm{d} t$ depends on the time history of both $A(t)$ and $T(t)$ as their effects propagate into the firn. We assume the compaction effects of $A(t)$ and $T(t)$ are separable 


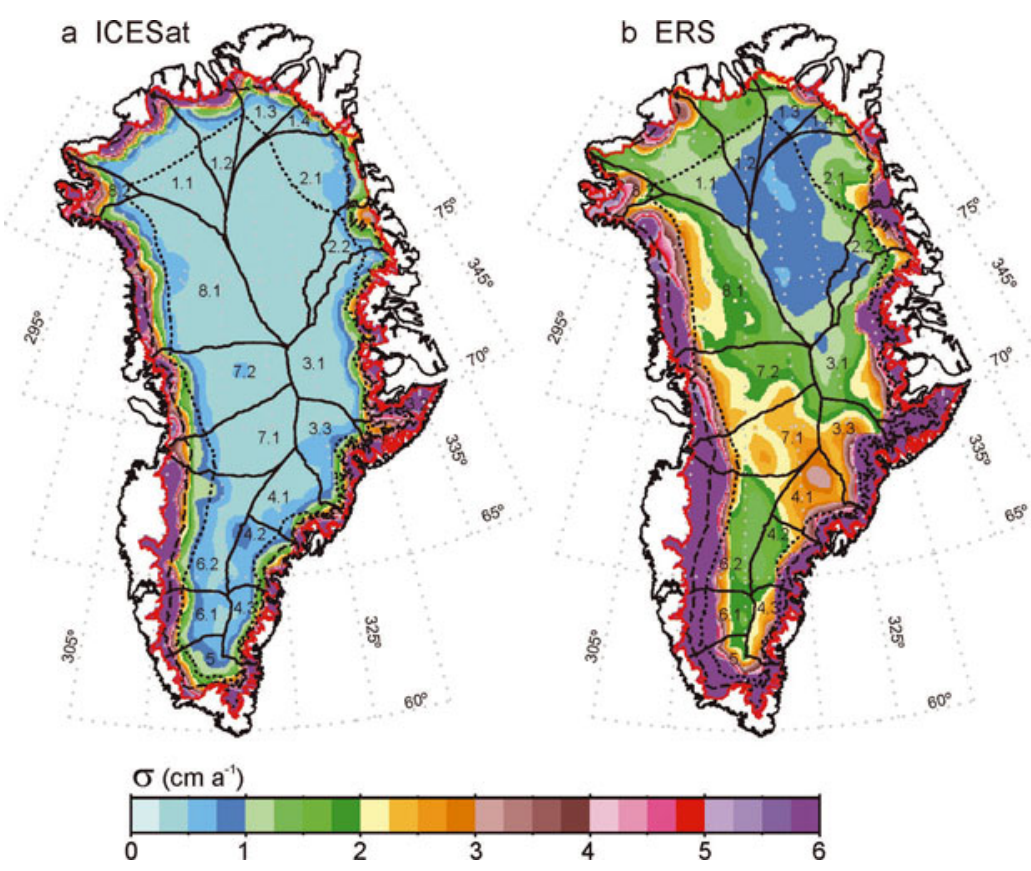

Fig. 5. (a) Maps of $\sigma_{\mathrm{d} H / \mathrm{d} t}$ for ICESat 2003-07 computed from the cell-average $\mathrm{d} H / \mathrm{d} t$ of the $\mathrm{d} h / \mathrm{d} t$ solutions at the individual reference points. (b) $\sigma_{\mathrm{d} H / \mathrm{d} t}$ for ERS 1992-2002 is computed from time-series analysis of crossover differences (Zwally and others, 2005).

so that

$$
\frac{\mathrm{d} C_{A T}}{\mathrm{~d} t}=\frac{\mathrm{d} C_{A}}{\mathrm{~d} t}+\frac{\mathrm{d} C_{T}}{\mathrm{~d} t}
$$

which should be valid at least for small $A(t)$ and $T(t)$ perturbations. The total elevation change from both $A(t)$ and $T(t)$ perturbations becomes

$$
\frac{\mathrm{d} H^{\mathrm{a}} C A T}{\mathrm{~d} t} \equiv \frac{\mathrm{d} H^{\mathrm{a}}}{\mathrm{d} t}+\frac{\mathrm{d} C_{A}}{\mathrm{~d} t}+\frac{\mathrm{d} C_{T}}{\mathrm{~d} t}=\frac{\mathrm{d} H^{\mathrm{a}} C A}{\mathrm{~d} t}+\frac{\mathrm{d} C_{T}}{\mathrm{~d} t},
$$

where $\mathrm{d} H^{\mathrm{a}}{ }_{C A} / \mathrm{d} t$ is the total change caused by $A(t)$, including the direct change and the change induced in the compaction rate. Equation (3) then gives

$$
\frac{\mathrm{d} l}{\mathrm{~d} t} \equiv \frac{\mathrm{d} H}{\mathrm{~d} t}-\frac{\mathrm{d} C_{T}}{\mathrm{~d} t}-\frac{\mathrm{d} B}{\mathrm{~d} t}=\frac{\mathrm{d} H^{\mathrm{a}} C A}{\mathrm{~d} t}+\frac{\mathrm{d} H_{\mathrm{b}}}{\mathrm{d} t}+\frac{\mathrm{d} H_{\mathrm{d}}}{\mathrm{d} t}
$$

where $d / / d t$ is an approximation of the change in thickness of the ice column, defined by treating $\mathrm{d} B / \mathrm{d} t$ and $\mathrm{d} C_{T} / \mathrm{d} t$ as corrections to $\mathrm{d} H / \mathrm{d} t$.

In Equation (6), the three terms on the right-hand side involve changes in mass, and

$$
\begin{aligned}
\frac{\mathrm{d} M}{\mathrm{~d} t} & =\left[\rho_{\mathrm{a}} \frac{\mathrm{d} H^{\mathrm{a}} C A}{\mathrm{~d} t}+\rho_{\mathrm{i}} \frac{\mathrm{d} H_{\mathrm{bd}}}{\mathrm{d} t}\right] \operatorname{Ar} f \\
& =\left[\frac{\rho_{\mathrm{a}} \mathrm{d} H^{\mathrm{a}} C A}{\mathrm{~d} t}+\rho_{\mathrm{i}}\left(\frac{\mathrm{d} I}{\mathrm{~d} t}-\frac{\mathrm{d} H^{\mathrm{a}} C A}{\mathrm{~d} T}\right)\right] \operatorname{Ar},
\end{aligned}
$$

where $\rho_{\mathrm{a}}$ is the appropriate density for the $A(t)$-driven changes, $\rho_{\mathrm{i}}$ is the density of ice appropriate for the ablation and dynamic terms (combined as $\mathrm{d} H_{\mathrm{bd}} / \mathrm{d} t \equiv\left(\mathrm{d} H_{\mathrm{b}} / \mathrm{d} t\right)+\left(\mathrm{d} H_{\mathrm{d}} /\right.$ $\mathrm{d} t)$ ), $\mathrm{Ar}$ is the area of a firn/ice column or map gridcell, and $f$ is the fraction of the cell inside the ice-sheet boundary. We use $\rho_{\mathrm{i}}=0.90$ for the typical density of glacier ice in the ablation zone and 0.91 in the accumulation zone, taking into account small variations from the 0.917 density of solid ice due to air content. $d M / d t$ is also used in units of mass change per unit area, which is defined as the surface flux equivalent (SFE). The SFE is equal to the negative of the mass-flux change at the surface that would be required for the ice column to be in balance. Maps of $d M / d t$ are presented in SFE units of $\mathrm{Gta}^{-1}(100 \mathrm{~km})^{-2}$, where $\mathrm{Gta}^{-1}(100 \mathrm{~km})^{-2}=100 \mathrm{~kg} \mathrm{a}^{-1} \mathrm{~m}^{-2}$.

\subsection{Separation of accumulation and melting/ice- dynamic driven mass changes}

An important aspect of our formulation is the separation of total $\mathrm{d} M / \mathrm{d} t$ into two components: $\mathrm{d} M_{\mathrm{a}} / \mathrm{d} t=\rho_{\mathrm{a}} \mathrm{d} H^{\mathrm{a}}{ }_{C A} / \mathrm{d} t$, which is driven by $A(t)$ perturbations, and $\mathrm{d} M_{\mathrm{bd}} / \mathrm{d} t=\rho_{\mathrm{i}}\left(\mathrm{d} H_{\mathrm{bd}} /\right.$ $\mathrm{dt}$ ), which is driven by ice dynamics and by ice ablation below the equilibrium line (EL). The EL varies from $\sim 1000 \mathrm{~m}$ in the south, to $1600 \mathrm{~m}$ around $72^{\circ} \mathrm{N}$, to $200 \mathrm{~m}$ in the north (Zwally and Giovinetto, 2001). Above the $\mathrm{EL}, \mathrm{d} H_{\mathrm{b}} / \mathrm{d} t=0$ and we use $\mathrm{d} H_{\mathrm{bd}} / \mathrm{d} t=\mathrm{d} H_{\mathrm{d}} / \mathrm{d} t$.

The primary value in Equations (6) and (7) is $\mathrm{d} H / \mathrm{d} t$ measured over some time, $\Delta t$. For $\mathrm{d} B / \mathrm{d} t$, we use the radial components of three models of isostatic rebound (Ivins and others, 2001; Huybrechts, 2002; Peltier, 2004), labeled (dB/ $\mathrm{d} t)_{1, \mathrm{H}, \mathrm{P}}$ respectively, interpolated to our gridpoints. As in Zwally and others (2005), we weight these models to account for distributions that showed similar patterns, specifically $\mathrm{d} B / \mathrm{d} t=\left[(\mathrm{dB} / \mathrm{dt})_{\mathrm{P}} / 4\right]+\left[(\mathrm{d} B / \mathrm{d} t)_{H} / 4\right]+\left[(\mathrm{d} B / \mathrm{d} t)_{1} / 2\right]$. We obtain the values of $\rho_{\mathrm{a}}, \mathrm{d} H^{\mathrm{a}}{ }_{C A} / \mathrm{d} t$ and $\mathrm{d} C_{T} / \mathrm{d} t$ from our firn-compaction model (Zwally and Li, 2002), which was modified to include the effects of surface melting and percolation ( $\mathrm{Li}$ and others, 2007) and is further modified here to include a variable accumulation rate, $A(t)$, as described in more detail by Li and Zwally (in press). The model is driven by a $T(t)$ temperature record from 1982 to the present as derived from Advanced Very High Resolution Radiometer (AVHRR) satellite measurements (Comiso, 2003) with values extended and updated using new calibrations.

We parameterize the accumulation perturbations, $A(t)-\langle A\rangle$, as a function of $T(t)$ using a sensitivity of $(5 \pm 1.5) \% \delta \mathrm{A} \mathrm{K}^{-1}$. The Intergovernmental Panel on Climate Change (IPCC) report (Solomon and others, 2007) summarized the sensitivity of accumulation rate to temperature with a range of $4.7-8.5 \% \delta \mathrm{A} \mathrm{K}^{-1}$. Data from Greenland ice cores (Clausen and others, 1988) give a range of $4-6 \% \delta \mathrm{A} \mathrm{K}^{-1}$ using 
a ERS/ATM dl/dt

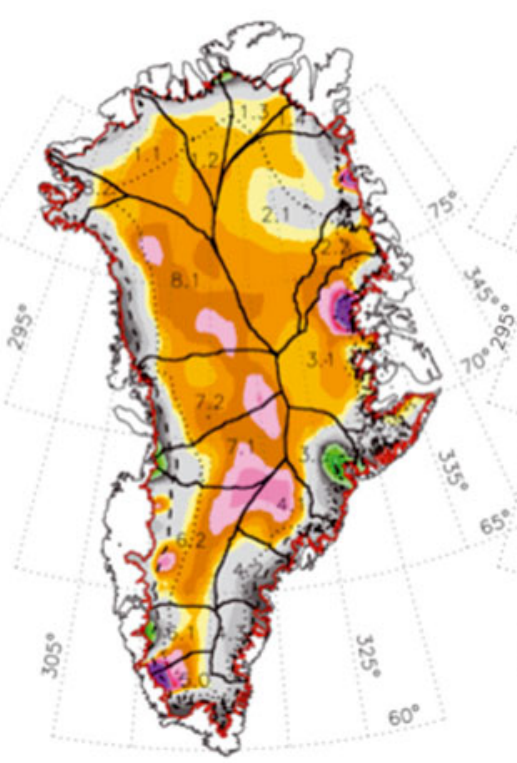

b ICESat $\mathrm{dl} / \mathrm{dt}$

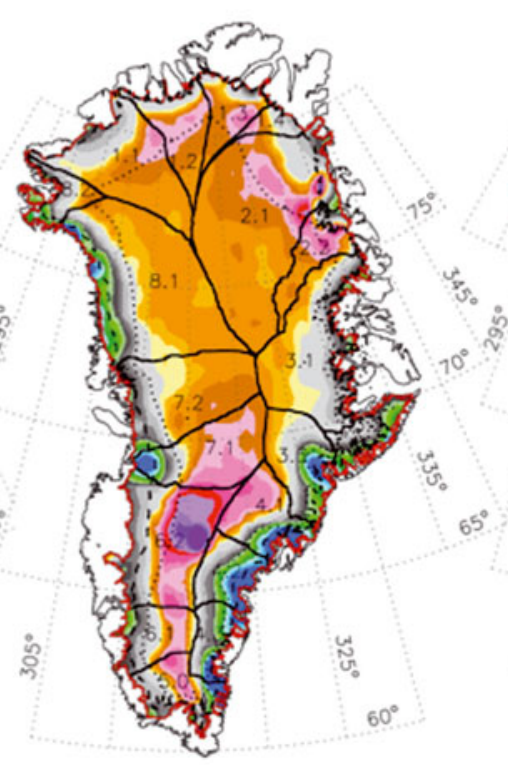

\section{c ICESat - ERS/ATM}

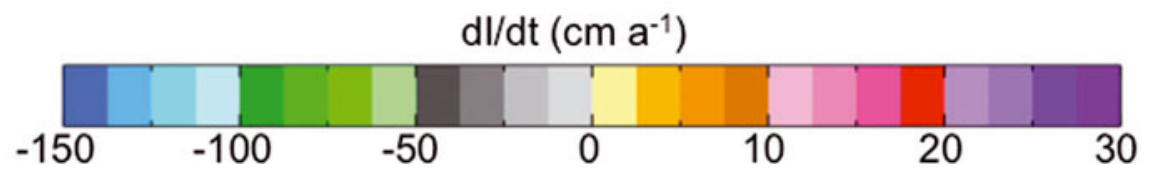

Fig. 6. (a) Distribution of $\mathrm{d} / / \mathrm{d} t$ for 1992-2002 derived from ERS/ATM (Zwally and others, 2005). (b) Distribution of $\mathrm{d} / / \mathrm{d} t$ for 2003-07 from ICESat. (c) Change in $\mathrm{d} / \mathrm{d} t$ between 1992-2002 and 2003-07. Increased thinning is evident around most of the margins. Increased thickening is shown in the northern drainage systems (DS1 and DS2) and at higher elevations in the south (DS5 and DS6). The central region has a small thinning above $\sim 2000 \mathrm{~m}$ in the latter period.

a sensitivity of $\delta^{18} \mathrm{O}$ to temperature of $0.69 \% \mathrm{~K}^{-1}$ (Zwally and Giovinetto, 1997). For 1988-2005, our $T(t)$ data and $A(T(t))$ parameterization give an $A(t)$ increase of $0.6 \% \mathrm{a}^{-1}$. This rate is close to the $0.7 \% \mathrm{a}^{-1}$ we calculate for $1988-2004$ from results of a regional-climate and surface mass-balance model using linear fits to the trends in the percolation and dry-snow zones given in figure 11 a of Box and others (2006) with zone areas weighted by $30 \%$ and $70 \%$.

\subsection{Density, $\rho_{\mathrm{a}}$, for accumulation-driven mass changes}

Our compaction model first calculates $\mathrm{d} H^{\mathrm{a}}{ }_{C A T} / \mathrm{d} t$ using both $T(t)$ and $A(t)$, and then calculates $\mathrm{d} C_{T} / \mathrm{d} t$ using $T(t)$ with constant $\langle A\rangle$. Equation (5) then gives the $\mathrm{d} H^{\mathrm{a}}{ }_{C A} / \mathrm{d} t$, and $\mathrm{d} H_{\mathrm{bd}} / \mathrm{d} t$ is the residual part of $\mathrm{d} H / \mathrm{d} t$ according to Equation (6). Equation (6) gives $\mathrm{d} / / \mathrm{d} t$ for calculation of $\mathrm{d} M / \mathrm{d} t$ in Equation (7), with all values calculated as averages over $\Delta t$. The average $\rho_{\mathrm{a}}$ is calculated over $\Delta t$ from $\rho_{\mathrm{a}}=\Delta M_{A} / \Delta H^{\mathrm{a}}{ }_{C A}$, where $\Delta M_{A}$ and $\Delta H^{\mathrm{a}}{ }_{C A}$ are the integrals over $\Delta t$ of $(A(t)-\langle A\rangle)$ and $\mathrm{d} H^{\mathrm{a}}{ }_{C A} / \mathrm{d} t$. Our calculated $\rho_{\mathrm{a}}$ is 0.525 for 1992-2002 and 0.527 for 2003-07, averaged over the ice sheet above the EL. The distribution of $\rho_{\mathrm{a}}$ in Figure 7c shows that $\rho_{\mathrm{a}}$ is generally smaller (e.g. $\left.<0.5\right)$ in the northern part of the ice sheet and toward higher elevations where lower $A$ reduces the rate of firn compaction. The largest values of $\rho_{\mathrm{a}}$ (e.g. $>0.65$ ) are in the areas with high $A$ at lower elevations mostly in the southern part.

Previous estimates of $\mathrm{d} M / \mathrm{d} t$ from $\mathrm{d} H / \mathrm{d} t$ made by various authors assumed there is an effective density, $\rho_{\text {eff, so that }}$ $\mathrm{d} M / \mathrm{d} t=\rho_{\text {eff }} \mathrm{d} l / \mathrm{d} t$, or when firn compaction terms are neglected $\mathrm{d} / \mathrm{d} / \mathrm{d} t=\rho_{\text {eff }}(\mathrm{d} H / \mathrm{dt}-\mathrm{d} B / \mathrm{d} t)$. For example, we previously used a density of 0.90 , which is appropriate for solid ice if all the $\mathrm{d} H / \mathrm{d} t$ is from long-term changes, and we illustrated a lower $\mathrm{d} M / \mathrm{d} t$ estimate using $\rho=0.4$, which is appropriate if all the $\mathrm{d} H / \mathrm{d} t$ is from the addition or depletion of the upper part of the firn (Zwally and others, 2005). Other authors used values ranging from 0.35 to 0.917 (e.g. 0.35 in Davis and others (2005); 0.300 for the 'interior' and 0.900 to 'seaward' in Thomas and others (2006); and 0.350 and 0.917 in Wingham and others (2006)). However, Equation (7) shows that $\rho_{\text {eff }}$ is strictly valid only if $A(t)$ is constant, so that $\mathrm{d} H^{\mathrm{a}}{ }_{C A} / \mathrm{d} t=0$ and $\rho_{\text {eff }}=0.9$. Calculations of $\mathrm{d} M / \mathrm{d} t$ using Equation (7) show that in some locations $\rho_{\text {eff }}$ values calculated using $(\mathrm{d} M / \mathrm{d} t) /(\mathrm{d} l / \mathrm{d} t)$ are unrealistically outside the 0.3-0.91 range for firn/ice densities. Therefore, using a fixed value of $\rho_{\text {eff }}$ is only valid if $A(t)$ variations are insignificant (i.e when $\mathrm{d} H^{\mathrm{a}}{ }_{C A} / \mathrm{d} t=0$ and $\rho_{\text {eff }}=0.9$ ). Consistent with this conclusion, Helsen and others (2008) used a compaction model based on the model of Zwally and Li (2002) and showed that a significant portion of the $d H / d t$ observed in East Antarctica can be caused by temporal variations in accumulation.

\section{RESULTS}

The spatial distributions of our calculated $\mathrm{d} C_{T} / \mathrm{d} t$ and $\mathrm{d} / / \mathrm{d} t$ for 2003-07 are given in Figure $4 \mathrm{~b}$ and c. Although $\mathrm{d} C_{T} / \mathrm{d} t$ is generally smaller than $\mathrm{d} H / \mathrm{d} t$, the larger values of $\mathrm{d} / / \mathrm{d} t$ evident at higher elevations, in particular, are a result of warmer temperatures increasing the rate of firn compaction. We also recalculate $\mathrm{d} C_{T} / \mathrm{d} t$ and $\mathrm{d} / / \mathrm{d} t$ for the $1992-2002$ period using the $\mathrm{d} H / \mathrm{d} t$ from Zwally and others (2005), and compare the $d / / d t$ for the two periods in Figure $6 a$ and $b$, with their difference in Figure 6c. To compare the rates of 


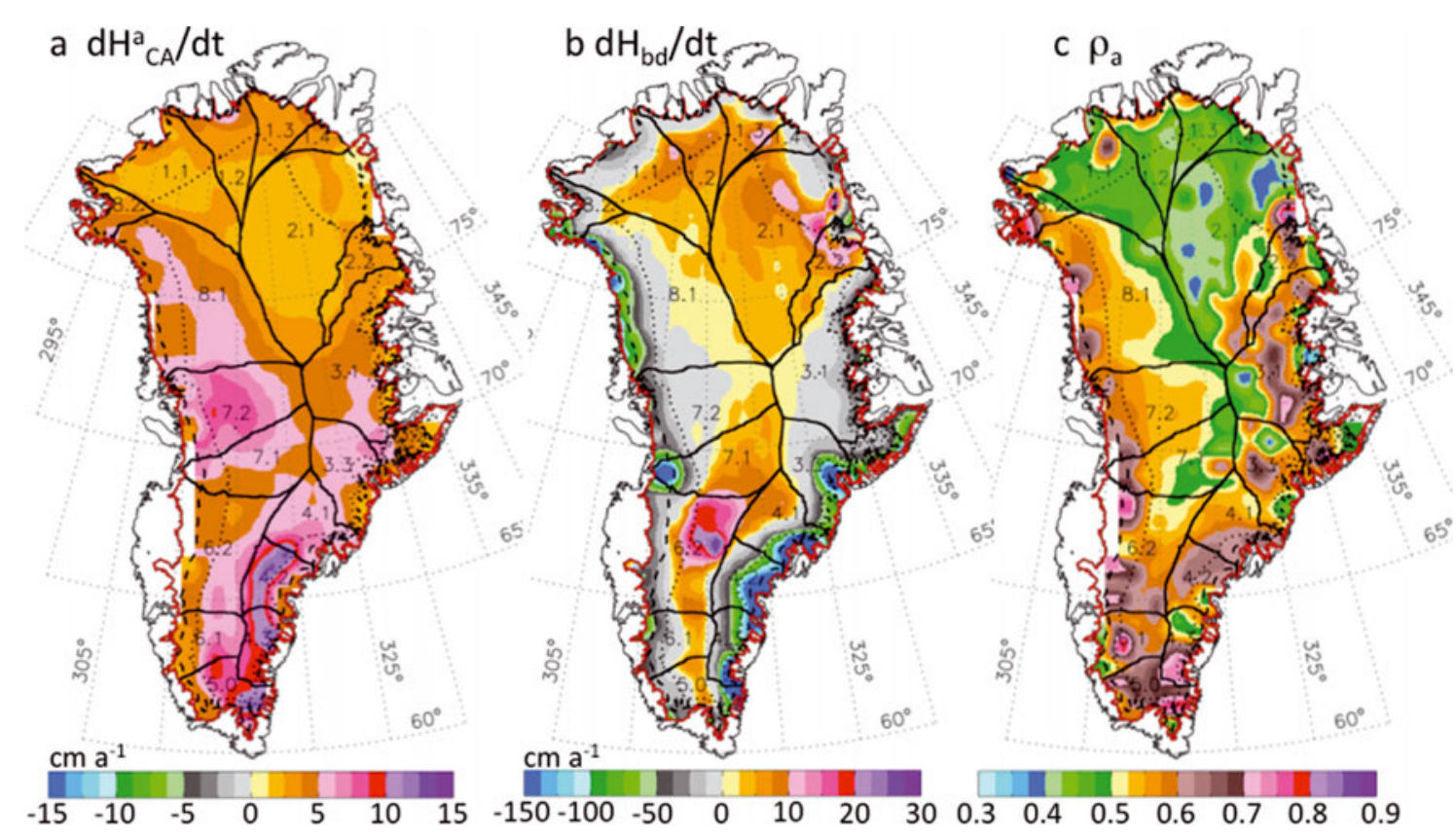

Fig. 7. Maps for the 2003-07 period. (a) Accumulation-driven elevation change, $\mathrm{d} H^{\mathrm{a}}{ }_{C A} / \mathrm{d} t$. (b) Ablation- and dynamic-driven elevation change, $\mathrm{d} H_{\mathrm{bd}} / \mathrm{d} t$. (c) Relative density, $\rho_{\mathrm{A}}$, of the firn for the $\mathrm{d} H^{\mathrm{a}} \mathrm{CA} / \mathrm{d} t$ component.

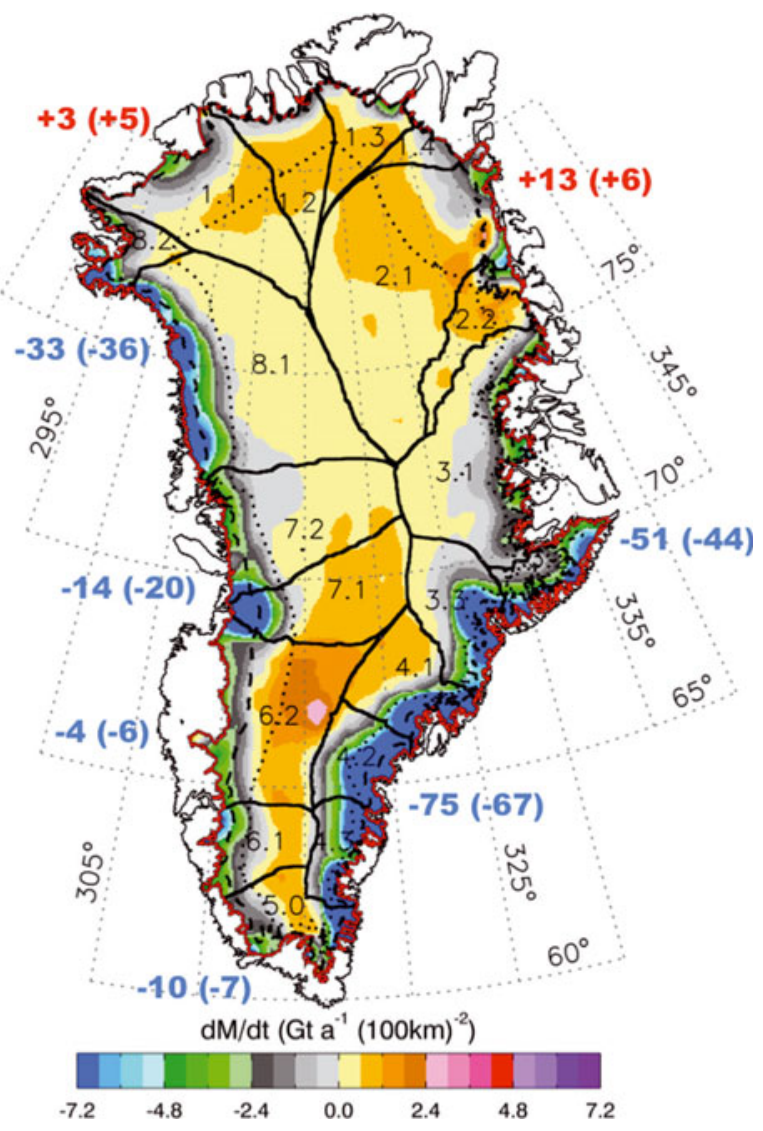

Fig. 8. Map of $\mathrm{d} M / \mathrm{d} t\left(\mathrm{Gt} \mathrm{a}^{-1}(100 \mathrm{~km})^{-2}\right)$ for 2003-07 derived from ICESat data. The numbers around the map are the net gains (red) or losses (blue) $\left(\mathrm{Gt} \mathrm{a}^{-1}\right)$ for the DS1-DS7. The numbers in parentheses are the changes from the 1992-2002 period. All drainage systems except DS5 are divided into subsystems (e.g. DS1.1, etc.). The largest increases in the rates of mass loss are in the west central region and the southeast. The northern DS1 and DS2 are gaining mass. Most of the areas above and below $2000 \mathrm{~m}$ (dotted curve) are gaining and losing mass, respectively. Mass losses below the EL (dashed curve) are from a combination of increased melting and acceleration of outlet glaciers. ice-sheet thickness change, the comparison of $\mathrm{d} / / \mathrm{d} t$ is more meaningful than comparison of $\mathrm{d} H / \mathrm{d} t$ maps, because of the magnitude of $\mathrm{d} C_{T} / \mathrm{d} t$ that changed with climate warming between the respective periods.

During 1992-2002, much of the ice sheet was shown to be thinning below $2000 \mathrm{~m}$ elevation and thickening above $2000 \mathrm{~m}$. During 2003-07, the largest changes in $\mathrm{d} / / \mathrm{d} t$ are the increases in thinning along most of the ice-sheet margin below the EL and below $2000 \mathrm{~m}$. Above $2000 \mathrm{~m}$, increased thickening is observed in the southwest drainage systems (DS5 and DS6) and in the northeast (DS1.2, DS1.3 and DS2). However, this increased thickening is mostly counterbalanced by a large area of small thinning in the central region.

The distributions of $\mathrm{d} H^{\mathrm{a}}{ }_{C A} / \mathrm{d} t, \mathrm{~d} H_{\mathrm{bd}} / \mathrm{d} t$ and $\rho_{\mathrm{a}}$ for 200307 are shown in Figure $7 \mathrm{a}-\mathrm{c}$. The resulting distribution of $\mathrm{d} M / \mathrm{d} t$ is in Figure 8, and the map of the calculated error, $\sigma_{\mathrm{d} M / \mathrm{d} t}$ is in Figure 9a, along with the $\sigma_{\mathrm{d} M / \mathrm{d} t}$ for $1992-2002$ in Figure $9 \mathrm{~b} . \sigma_{\mathrm{d} M / \mathrm{d} t}$ is calculated using propagation of errors, $\sigma_{y}{ }^{2}=\Sigma\left(\partial y / \partial x_{i} \sigma_{i}\right)^{2}$, which applied to Equation (7) gives

$$
\begin{aligned}
& \left(\sigma_{\mathrm{d} M / \mathrm{d} t}\right)^{2}=\left(\operatorname{Ar} f \rho_{\mathrm{i}}\right)^{2}\left\{\rho_{\mathrm{i}}^{2}\left[\sigma_{\mathrm{d} H / \mathrm{d} t}{ }^{2}+\sigma_{\mathrm{d} C T / \mathrm{d} t}{ }^{2}+\sigma_{\mathrm{d} B / \mathrm{d} t}{ }^{2}\right]\right. \\
& \left.+\left[\left(\rho_{\mathrm{i}}-\rho_{\mathrm{a}}\right) \sigma_{\mathrm{d} H \mathrm{a} C A / \mathrm{d} t}\right]^{2}+\left[\sigma_{\rho \mathrm{a}} \frac{\mathrm{d} H^{\mathrm{a}} C A}{\mathrm{~d} t}\right]^{2}\right\} .
\end{aligned}
$$

For ICESat, $\sigma_{\mathrm{d} H / \mathrm{d} t}$ in Figure $5 \mathrm{a}$ is computed from the cellaverage $\mathrm{d} H / \mathrm{d} t$ of the $\mathrm{d} h / \mathrm{d} t$ solutions at the individual reference points. For ERS, $\sigma_{\mathrm{d} H / \mathrm{d} t}$ in Figure $5 \mathrm{~b}$ is computed from the time-series analysis of crossover differences (Zwally and others, 2005). $\sigma_{\mathrm{d} C T / \mathrm{d} t}$ is calculated from the fit of $C_{T}(t)$ for the appropriate period (October 2003-October 2007 for ICESat and April 1992-October 2001 for ERS), as the uncertainty in the time derivative in $C_{T}(t)=a+\left(d C_{T} / \mathrm{d} t\right) t+$ $c \sin (\omega t)+d \cos (\omega t)$, where $\omega=2 \pi / 365.25$ and $t$ is in days. $\sigma_{\mathrm{d} B / \mathrm{d} t}$ is computed as half the difference between the similar and different values used to compute $\mathrm{d} B / \mathrm{d} t . \sigma_{\mathrm{d} H^{\mathrm{a}} C A / \mathrm{d} t}$ is the difference between $\mathrm{d} H^{\mathrm{a}}{ }_{C A} / \mathrm{d} t$ for the cases where 


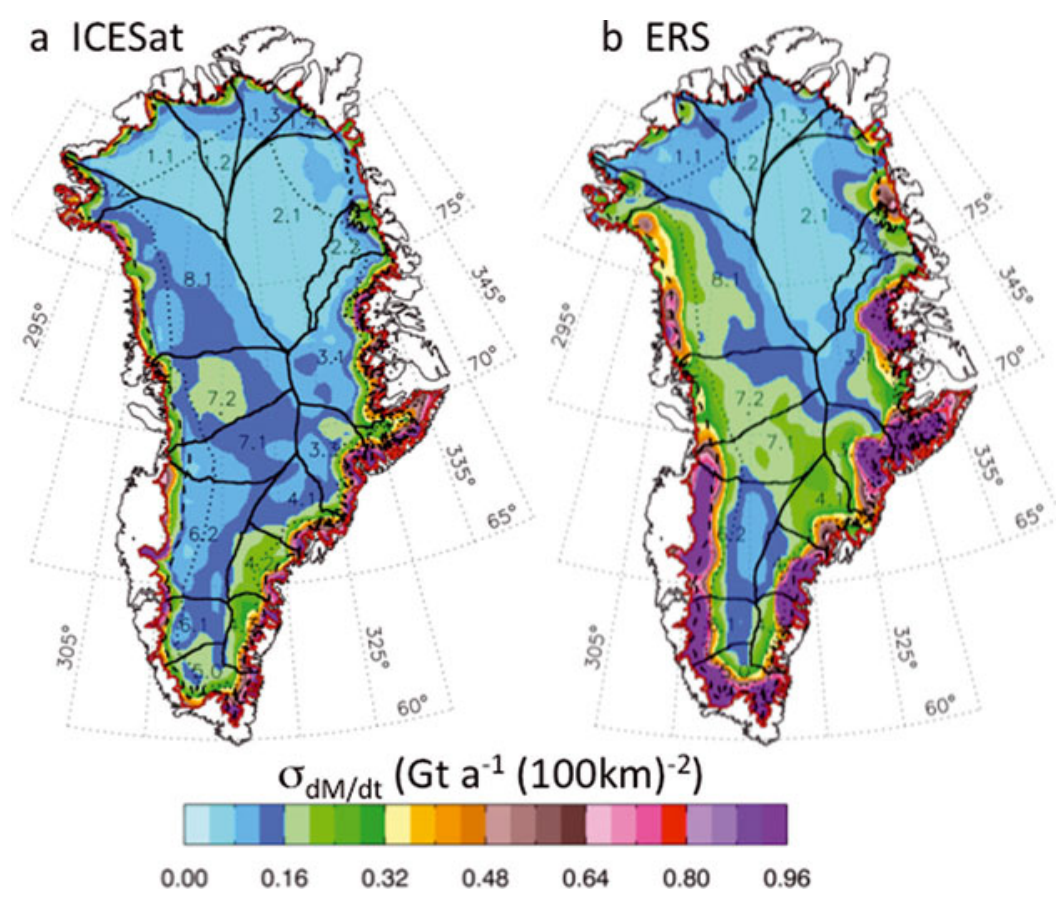

Fig. 9. (a) Maps of $\sigma_{\mathrm{d} M / \mathrm{d} t}$ (a) for 2003-07 from ICESat data and (b) for 1992-2002 from ERS and ATM data.

accumulation changes at a rate of $5 \% \mathrm{~K}^{-1}$ and $8 \% \mathrm{~K}^{-1} . \sigma_{\rho_{\mathrm{a}}}$ is the standard deviation of the distribution of $\rho_{\mathrm{a}}$.

The values of $\mathrm{d} H / \mathrm{d} t, \mathrm{~d} C_{T} / \mathrm{d} t, \mathrm{~d} / / \mathrm{d} t, \mathrm{~d} H^{\mathrm{a}} C_{C A} / \mathrm{d} t$ and $\mathrm{d} H_{\mathrm{bd}} / \mathrm{d} t$ as functions of elevation averaged over the ice sheet are shown in Figure 10. The importance of $\mathrm{d} C_{T} / \mathrm{d} t$ as a correction to $\mathrm{d} H / \mathrm{d} t$ is illustrated by the close agreement between $\mathrm{d} / / \mathrm{d} t$ values (5.2 vs $4.9 \mathrm{~cm} \mathrm{a}^{-1}$ ) for $1992-2002$ and 2003-07 respectively at elevations above $2200 \mathrm{~m}$, in contrast to the large difference between the $\mathrm{d} H / \mathrm{d} t$ values $\left(4.9 \mathrm{vs} 1.0 \mathrm{~cm} \mathrm{a}^{-1}\right)$. Without $\mathrm{d} C_{T} / \mathrm{d} t$, which is larger for the warmer 2003-07 period, the $\mathrm{d} H / \mathrm{d} t$ alone would have incorrectly suggested that the ice-sheet thickening of $\sim 5 \mathrm{~cm} \mathrm{a}^{-1}$ at higher elevations (Johannessen and others, 2005; Zwally and others,
2005) had significantly diminished. The average $\mathrm{d} C_{T} / \mathrm{d} t$ over the accumulation zone are -0.2 and $-4.1 \mathrm{~cm} \mathrm{a}^{-1}$ for 1992 2002 and 2003-07 respectively, and the associated volume changes of $-3 \mathrm{~km}^{3} \mathrm{a}^{-1}$ and $-59 \mathrm{~km}^{3} \mathrm{a}^{-1}$ would lower the derived $\mathrm{d} M / \mathrm{d} t$ by $3 \mathrm{Gta}^{-1}$ and $54 \mathrm{Gta}^{-1}$ if the $\mathrm{d} C_{T} / \mathrm{d} t$ correction to $\mathrm{d} H / \mathrm{d} t$ were not applied.

The average $\mathrm{d} B / \mathrm{d} t$ is $0.06 \mathrm{~cm} \mathrm{a}^{-1}$, which adjusts $\mathrm{d} M / \mathrm{d} t$ by $-1 \mathrm{Gta}^{-1}$. The close agreement of $\mathrm{d} / / \mathrm{d} t$ at high elevations averaged over the ice sheet between the two periods suggests that the laser and radar results are actually quite comparable, despite the time difference between the measurements and technical differences between the laser and radar measurements. There is also close agreement

Table 1. $\mathrm{d} M / \mathrm{d} t\left(\mathrm{Gt} \mathrm{a}^{-1}\right)$ by drainage system (DS): four DS in north and southwest (N SW; 1, 2, 5, 6), four DS in west central and southeast (WC $\mathrm{SE} ; 3,4,7,8)$ and totals. (Totals are rounded to integers after summation of values by DS before rounding)

DS

\begin{tabular}{|c|c|c|c|c|c|c|c|c|c|c|c|}
\hline DS & 8 & 7 & 6 & 5 & 4 & 3 & 2 & 1 & N SW & WC SE & Total \\
\hline \multicolumn{12}{|c|}{ 2003-07 } \\
\hline Total & -33 & -14 & -4 & -10 & -75 & -51 & 13 & 3 & 3 & -174 & $-171 \pm 4$ \\
\hline$>2000$ & 5 & 8 & 11 & 1 & -10 & -6 & 13 & 5 & 31 & -3 & $28 \pm 1$ \\
\hline$<2000$ & -38 & -23 & -15 & -10 & -65 & -45 & 0 & -2 & -28 & -171 & $-198 \pm 4$ \\
\hline$>\mathrm{EL}$ & -9 & 0 & 8 & -3 & -39 & -25 & 17 & 5 & 27 & -72 & $-46 \pm 2$ \\
\hline$<\mathrm{EL}$ & -24 & -15 & -12 & -6 & -37 & -26 & -4 & -2 & -24 & -101 & $-125 \pm 3$ \\
\hline \multicolumn{12}{|c|}{ 1992-2002 } \\
\hline Total & 3 & 6 & 1 & -3 & -9 & -9 & 6 & -2 & 1 & -8 & $-7 \pm 3$ \\
\hline$>2000$ & 11 & 12 & 6 & 0 & 0 & 3 & 9 & 4 & 18 & 26 & $44 \pm 1$ \\
\hline$<2000$ & -7 & -6 & -5 & -3 & -9 & -12 & -3 & -6 & -16 & -35 & $-51 \pm 3$ \\
\hline$>\mathrm{EL}$ & 9 & 11 & 6 & -1 & -3 & -2 & 7 & 0 & 12 & 15 & $26 \pm 3$ \\
\hline$<\mathrm{EL}$ & -6 & -6 & -5 & -2 & -6 & -6 & -2 & -2 & -10 & -23 & $-33 \pm 1$ \\
\hline \multicolumn{12}{|c|}{ Change from 1992-2002 to 2003-07 } \\
\hline Total & -36 & -20 & -5 & -6 & -66 & -42 & 7 & 5 & 2 & -165 & $-164 \pm 5$ \\
\hline$>2000$ & -6 & -4 & 5 & 1 & -10 & -9 & 5 & 1 & 13 & -29 & $-16 \pm 1$ \\
\hline$<2000$ & -30 & -16 & -10 & -7 & -56 & -33 & 2 & 4 & -11 & -136 & $-147 \pm 5$ \\
\hline$>\mathrm{EL}$ & -18 & -11 & 3 & -2 & -35 & -22 & 10 & 5 & 15 & -87 & $-72 \pm 3$ \\
\hline$<\mathrm{EL}$ & -18 & -9 & -7 & -4 & -31 & -20 & -2 & 0 & -14 & -78 & $-92 \pm 3$ \\
\hline
\end{tabular}




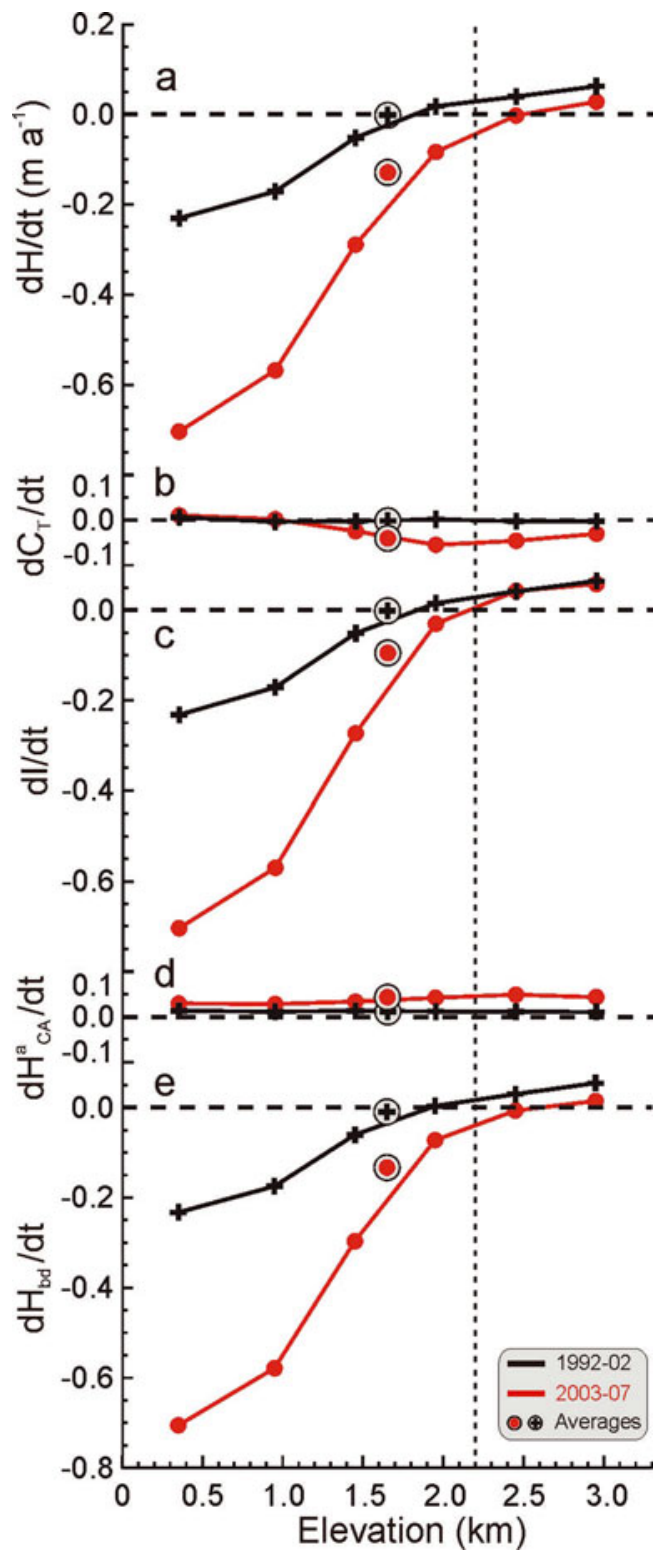

Fig. 10. All parameters averaged in $500 \mathrm{~m}$ elevation bands over the ice sheet versus elevations for 1992-2002 and 2003-07. Averages are over all elevations weighted by area. (a) Measured $\mathrm{d} H / \mathrm{d} t$ decreased with time at all elevations. (b) Firn-compaction correction $\mathrm{d} C_{T} / \mathrm{d} t$ driven by temperature variations only. (c) $\mathrm{d} / / \mathrm{d} t=$ $(\mathrm{d} H / \mathrm{d} t)-\left(\mathrm{d} C_{T} / \mathrm{d} t\right)-(\mathrm{d} B / \mathrm{d} t)$ shows little change with time above $2200 \mathrm{~m}$. (d) $\mathrm{d} H^{\mathrm{a}}{ }_{C A} / \mathrm{d} t$, the portion of $\mathrm{d} / / \mathrm{d} t$ driven by accumulation variations, increased slightly at all elevations. (e) $\mathrm{d} H_{\mathrm{bd}} / \mathrm{d} t$, the portion of $\mathrm{d} / \mathrm{d} t$ driven by changes in ablation (below EL only) and ice dynamics, decreased at all elevations. The increased thinning below the EL is from increased melting and acceleration of outlet glaciers. The increase in dynamic thinning extends inland to the highest elevations.

(Fig. 11) between the two periods in both the derived $\mathrm{d} M_{\mathrm{bd}} / \mathrm{d} t$ and the $\mathrm{d} M / \mathrm{d} t$ at all elevations in four (DS1, DS2, DS5 and DS6) of the eight drainage systems, with average values being slightly higher in DS1 and DS2 and slightly lower in DS5 and DS6 in the latter period.

The distribution of $\mathrm{d} / \mathrm{M} / \mathrm{d} t$ (Figs 8 and 11; Table 1) shows that during 2003-07 most of the GIS above $2000 \mathrm{~m}$ was gaining mass $\left(+28 \pm 1 \mathrm{Gt} \mathrm{a}^{-1}\right)$ and most of it below $2000 \mathrm{~m}$ was losing mass $\left(-198 \pm 4 \mathrm{Gta}^{-1}\right)$. Both these rates are lower than the 1992-2002 values of $+44 \pm 1 \mathrm{Gta}^{-1}$ and

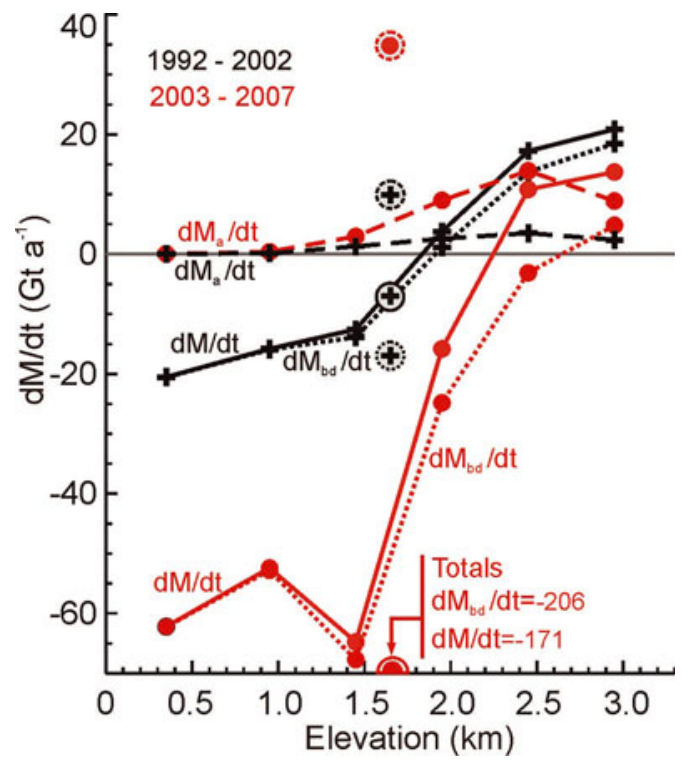

Fig 11. $\mathrm{d} M / \mathrm{d} t$ is total rate of mass change, $\mathrm{d} M_{\mathrm{a}} / \mathrm{d} t$ is the component driven by temporal variations in snow accumulation, and $\mathrm{d} M_{\mathrm{bd}} / \mathrm{d} t$ is the component driven by ablation and ice dynamics, all averaged by $500 \mathrm{~m}$ elevation bands over the ice sheet for the 1992-2002 and 2003-07 periods. Circled symbols are totals for all elevations weighted by area.

$-51 \pm 3 \mathrm{Gta}^{-1}$. The total loss of $171 \pm 4 \mathrm{Gta}^{-1}$ during 200307 is in close agreement with two GRACE-based loss rates for similar time periods of $158 \pm 8 \mathrm{Gt} \mathrm{a}^{-1}$ for October 2003November 2007 (Luthcke and others, 2009) and $179 \pm$ $25 \mathrm{Gta}^{-1}$ for February 2003-January 2008 (Wouters and others, 2008). Our derived mass loss of $171 \pm 4 \mathrm{Gta}^{-1}$ represents an increased loss rate of $164 \pm 5 \mathrm{Gt} \mathrm{a}^{-1}$ compared with the near-balance conditions during 1992-2002, for which we obtain a revised small loss of $7 \pm 3 \mathrm{Gta}^{-1}$. The previous small gain (Zwally and others, 2005) of $11 \mathrm{Gta}^{-1}$ is revised here due to several factors: $-13.8 \mathrm{Gta}^{-1}$ change is from improvements in the firn-compaction model, $-9.2 \mathrm{Gta}^{-1}$ from use of recalibrated $T(t)$ data, $+11.9 \mathrm{Gta}^{-1}$ from changes in the grid-map projection and use of partial gridcells at the ice edge, and $7.8 \mathrm{Gt} \mathrm{a}^{-1}$ from partitioning of the height changes into accumulation-driven changes with an average density of 0.53 and ablation-/dynamic-driven changes with an average density of 0.9 .

Our partitioning of the $\mathrm{d} M / \mathrm{d} t$ gives an accumulationdriven gain $\left(\mathrm{d} M_{\mathrm{a}} / \mathrm{d} t\right)$ of $35 \mathrm{Gta}^{-1}$ for 2003-07, compared with a gain of $10 \mathrm{Gta}^{-1}$ during 1992-2002 (Fig. 11). The derived ablation-dynamic loss rate $\left(\mathrm{d} / M_{\mathrm{bd}} / \mathrm{d} t\right)$ of $206 \mathrm{Gta}^{-1}$ for 2003-07 is much larger than the corresponding loss rate of $17 \mathrm{Gt} \mathrm{a}^{-1}$ during 1992-2002. Although both components of $\mathrm{d} M / \mathrm{d} t$ are larger in the later period, the increase in the loss term $\left(-189 \mathrm{Gta}^{-1}\right)$ from melting and ice dynamics strongly dominates the increase in the gain term $\left(+25 \mathrm{Gta}^{-1}\right)$ from snow accumulation. For comparison, if none of the mass change were ascribed to changes in accumulation, then net rate of mass loss for 2003-07 would be $<171 \mathrm{Gta}^{-1}$ (i.e. less negative than $-171 \mathrm{Gta}^{-1}$ ), because the positive $\mathrm{d} H^{\mathrm{a}}{ }_{C A} / \mathrm{d} t$ component of observed elevation change would have an associated density of 0.91 instead of 0.527 .

To calculate a sensitivity of the derived $\mathrm{d} M / \mathrm{d} t$ to our parameterization of $A(t)$, we ran the firn compaction for the 2003-07 period using a parameterization of $8 \% \delta \mathrm{A} \mathrm{K}^{-1}$ instead of $5 \% \delta \mathrm{AK}^{-1}$, which changed $\mathrm{d} M / \mathrm{d} t$ by 


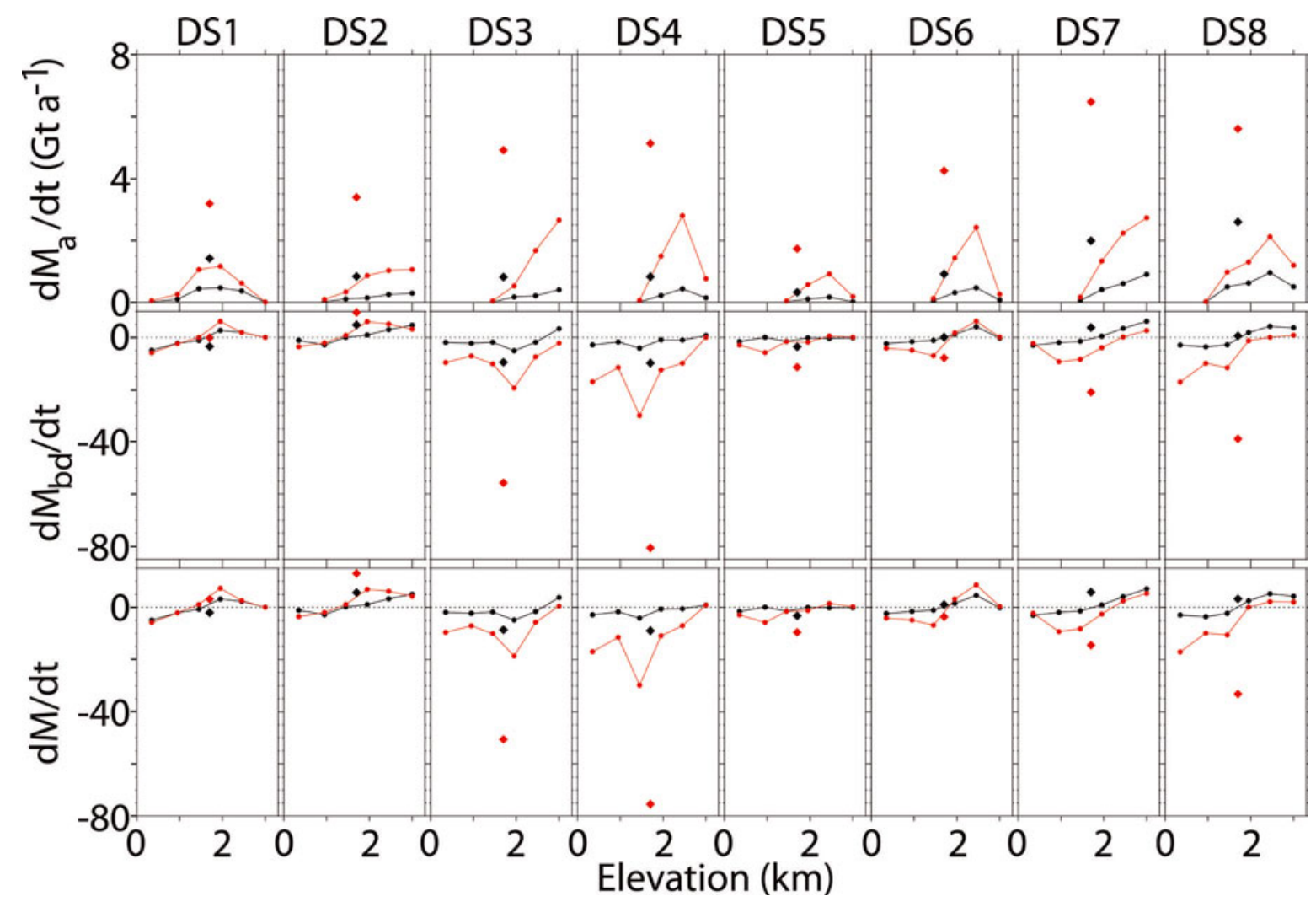

Fig. 12. Components of mass change by drainage system. $\mathrm{d} M_{\mathrm{a}} / \mathrm{d} t, \mathrm{~d} M_{\mathrm{bd}} / \mathrm{d} t, \mathrm{~d} M / \mathrm{d} t\left(\mathrm{Gt} \mathrm{a}{ }^{-1}\right)$ averaged over $500 \mathrm{~m}$ elevation bands for the eight drainage systems for 1992-2002 (black) and 2003-07 (red) with totals for 1992-2002 (black symbols) and 2003-07 (red symbols). Accumulation-driven mass increases are largest in DS3, DS4, DS7 and DS8, and dynamic-/ablation-driven thinning is largest in DS3, DS4 and DS8 and very small in DS1, DS2, DS5 and DS6.

$11 \mathrm{Gta}^{-1}$, giving a sensitivity of $-3.7 \mathrm{Gta}^{-1}(\% \delta A \mathrm{~K})^{-1}$. For 2003-07, the sensitivity can also be estimated by noting that a $\mathrm{d} M_{\mathrm{a}} / \mathrm{d} t$ value of $35 \mathrm{Gta}^{-1}$ would be $\sim 60 \mathrm{Gta}^{-1}$ (i.e. $(35 \times 0.91) / 0.527)$ if part of the measured elevation changes were not ascribed to increasing $A(t)$, giving a sensitivity of $(35-60) / 5=-5.0 \mathrm{Gta}^{-1}(\% \delta A \mathrm{~K})^{-1}$. For 1992-2002, the $\mathrm{d} \mathrm{M}_{\mathrm{a}} / \mathrm{d} t$ of $10 \mathrm{Gta}^{-1}$ would be $17 \mathrm{Gta}^{-1}$, giving $-1.4 \mathrm{Gta}^{-1}$ $(\% \delta A K)^{-1}$. Therefore, the sensitivity appears to depend somewhat on the specific $A(T(t))$ variability history.

The relative values of the $\mathrm{d} M_{\mathrm{a}} / \mathrm{d} t$ and $\mathrm{d} M_{\mathrm{bd}} / \mathrm{d} t$ components of $\mathrm{d} M / \mathrm{d} t$ vary significantly from one drainage system to another, as do their changes with time (Fig. 12). In the northern drainage systems (DS1 and DS2), $\mathrm{d} M_{\mathrm{bd}} / \mathrm{d} t$ values are essentially the same in both time periods, indicating little change in either the dynamics or the ablation in those systems. Also, $\mathrm{d} M_{\mathrm{bd}} / \mathrm{d} t$ is not large compared with $d M_{a} / d t$ in these drainage systems as it is in the southeast DS3 and DS4 and in the upper western DS7 and DS8 (note the $\mathrm{d} / M_{\mathrm{bd}} / \mathrm{d} t$ scale is ten times the $\mathrm{d} M_{\mathrm{a}} / \mathrm{d} t$ scale in Fig. 12). Although $\mathrm{d} M_{\mathrm{a}} / \mathrm{d} t$ increases with time in all drainage systems, consistent with the increase in $A(t)$, the increase in $\mathrm{d} M_{\mathrm{bd}} / \mathrm{d} t$ from dynamic thinning and ablation dominates those increases in $\mathrm{d} M_{\mathrm{a}} / \mathrm{d} t$ in all drainage systems except the northern DS1 and DS2.

\section{DISCUSSION}

\subsection{Ice-sheet interior}

Our results show that the part of the accumulation zone above $2000 \mathrm{~m}(60.8 \%$ by area) is thickening on average during both periods by similar amounts, as shown by a $\mathrm{d} / \mathrm{d} t$ value of $+4.78 \mathrm{~cm} \mathrm{a}^{-1}$ during 2003-07 and the slightly larger value of $+5.10 \mathrm{~cm} \mathrm{a}^{-1}$ during 1992-2002 (Fig. 10). Although $\mathrm{d} / / \mathrm{d} t$ is similar in both periods, the accumulation-driven part $\left(\mathrm{d} H^{\mathrm{a}} \mathrm{CA} / \mathrm{d} t\right)$ increased from +1.13 to $+4.68 \mathrm{~cm} \mathrm{a}^{-1}$ while the dynamic driven part $\left(\mathrm{d} H_{\mathrm{d}} / \mathrm{d} t\right)$ decreased from +3.96 to $+0.10 \mathrm{~cm} \mathrm{a}^{-1}$. Therefore, the changes at higher elevations $(>2000 \mathrm{~m})$ are a combination of ice thickening of $3.55 \mathrm{~cm} \mathrm{a}^{-1}$ from increased $A(t)$ and an approximately equal increase in dynamic thinning of $3.86 \mathrm{~cm} \mathrm{a}^{-1}$.

If the resulting $\mathrm{d} / / \mathrm{d} t$ decrease of $0.32 \mathrm{~cm} \mathrm{a}^{-1}$ were not partitioned between $\mathrm{d} H^{\mathrm{a}}{ }_{C A} / \mathrm{d} t$ and $\mathrm{d} H_{\mathrm{d}} / \mathrm{d} t$, it would imply a decrease in the rate of mass gain of only 2 or $3 \mathrm{Gta}^{-1}$. However, the partitioning gives a $\mathrm{d} M_{\mathrm{a}} / \mathrm{d} t$ increase of $20 \mathrm{Gta}^{-1}$ (i.e. gaining lower-density firn) and a larger $\mathrm{d} M_{\mathrm{d}} / \mathrm{d} t$ decrease of $36 \mathrm{Gt} \mathrm{a}^{-1}$ (i.e. losing higher-density ice), giving a net change of $-16.5 \mathrm{Gta}^{-1}$ above $2000 \mathrm{~m}$. Therefore, although the accumulation-driven thickening approximately balances the dynamic thinning (in terms of $\mathrm{cm} \mathrm{a}^{-1}$ ), the net effect is a decrease in the rate of mass gain from 44 to $28 \mathrm{Gta}^{-1}$.

The map of the $\mathrm{d} M / \mathrm{d} t$ distribution (Fig. 8), Table 1 and Figure 13 show that the northern DS1 and DS2 have net mass gains and have become slightly more positive during 2003-07 compared with 1992-2002. The four drainage systems in the north and southwest (DS1, DS2, DS5 and DS6) show increased mass-gain rates above $2000 \mathrm{~m}$ (+18 to $\left.+31 \mathrm{Gta}^{-1}\right)$, suggesting increases in rates of ice accumulation, and small increased loss rates at lower elevations $\left(-15\right.$ to $\left.-25 \mathrm{Gta}^{-1}\right)$. Overall, the major changes toward increased losses are in southeast DS3 and DS4 and west 


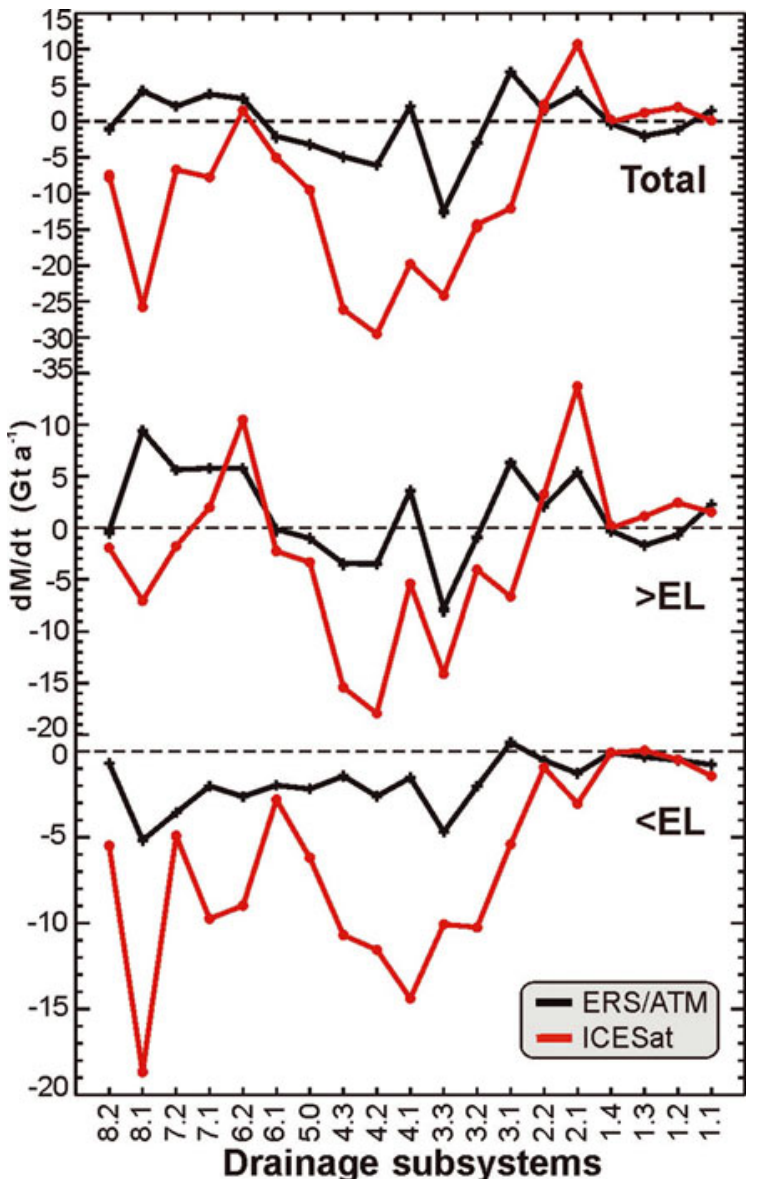

Fig. 13. Total rate of mass change and rates above and below EL by drainage subsystems.

central DS7 and DS8 in regions with accelerating glaciers (Rignot and Kanagaratnam, 2006). These four drainage systems have small negative changes above $2000 \mathrm{~m}$ (+26 to $-2 \mathrm{Gt} \mathrm{a}^{-1}$ ), but large changes at lower elevations ( -32 to $\left.-156 \mathrm{Gta}^{-1}\right)$.

\subsection{Ice-sheet margins and outlet glaciers}

Only $11.2 \%$ of the GIS area lies below the EL, and $39.2 \%$ lies below $2000 \mathrm{~m}$, but the change in mass loss at these lower elevations, from -33 to $-125 \mathrm{Gt} \mathrm{a}^{-1}$ below the EL and from -51 to $-198 \mathrm{Gt} \mathrm{a}^{-1}$ below $2000 \mathrm{~m}$ (Table 1), dominates the total mass balance for the whole ice sheet. Therefore, the lower elevations of the GIS have been mostly thinning, and this thinning has increased significantly in the later period (Figs 10-12). However, the increases below the EL in the northern DS1 and DS2 are small or near zero (Fig. 13).

The only locations around the margins that show thickening at lower elevations (Fig. 8) are the southeast corners of DS2.1 and DS2.2, a small area near Petermann Gletscher at the boundary between DS1.1 and DS1.2 and the small ice dome extending westward from the GIS at $66^{\circ} \mathrm{N}$ in DS6.2. In contrast, during 1992-2002, the pattern of thickening and thinning around the margin was more mixed, with areas of significant thickening in DS3.1 and DS5. Also, the thinning in the western ablation zone in DS6.2, DS7.2 and DS8.1 was small in 1992-2002 compared with 2003-07.

About $25 \mathrm{Gt} \mathrm{a}^{-1}$ or $5 \%$ of the total mass flux from the GIS is through Jakobshavn Isbræ (Rignot and Kanagaratnam, 2006), in DS7.1. During the 1990s, the mass gain of $5.8 \mathrm{Gt} \mathrm{a}^{-1}$ above

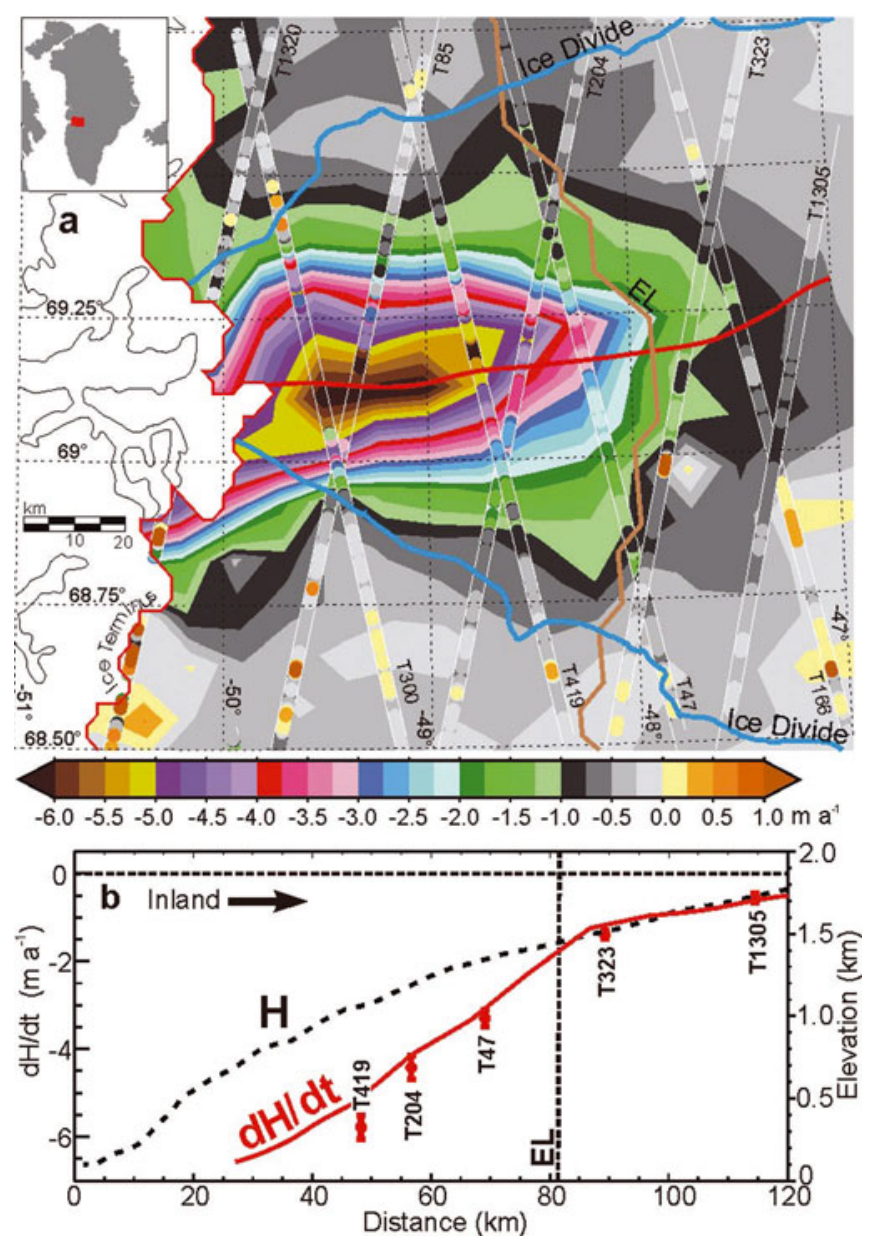

Fig. 14. (a) $\mathrm{d} H / \mathrm{d} t$ map of Jakobshavn Isbræ kriged on a $10 \mathrm{~km}$ grid from the along-track $\mathrm{d} h / \mathrm{d} t$ plotted on the tracks. (b) $\mathrm{d} H / \mathrm{d} t$ profile (interpolated from $\mathrm{d} H / \mathrm{d} t$ map) and $H$ profile along a central flowline (red curve in (a)). Red symbols are $\mathrm{d} h / \mathrm{d} t \pm \sigma_{\mathrm{d} h / \mathrm{d} t}$ at points where the flowline crosses the ICESat tracks. Steep increase in $\mathrm{d} H$ / $\mathrm{d} t$ below the EL indicates effect of increased melting as well as thinning from glacier acceleration.

the EL in DS7.1 exceeded the loss of $2.0 \mathrm{Gt} \mathrm{a}^{-1}$ below the EL. For 2003-07, the gain above the EL reduced to $2.0 \mathrm{Gta}^{-1}$, and the loss below increased to $9.7 \mathrm{Gt} \mathrm{a}^{-1}$. Therefore, the net balance changed from a gain of $3.8 \mathrm{Gta}^{-1}$ in the $1990 \mathrm{~s}$ to a loss of $7.8 \mathrm{Gta}^{-1}$, which accounts for $\sim 7 \%$ of the total increase in $\mathrm{d} / \mathrm{M} / \mathrm{d} t$ between the two periods.

Figures 14a, 15a, 16a and 17a show $\mathrm{d} / \mathrm{H} / \mathrm{d} t$ maps of four outlet glaciers kriged from the along-track $\mathrm{d} h / \mathrm{d} t$ at higher resolution $(10 \mathrm{~km}, 5 \mathrm{~km}, 500 \mathrm{~m}$ and $500 \mathrm{~m}$, respectively) than the $50 \mathrm{~km}$ used for $\mathrm{d} M / \mathrm{d} t$ calculations and analysis. Figures $14 \mathrm{~b}, 15 \mathrm{~b}, 16 \mathrm{~b}$ and $17 \mathrm{~b}$ show a comparison between the $d h / d t$ at intersections of a central flowline with the ICESat tracks and $\mathrm{d} H / \mathrm{d} t$ interpolated from the higherresolution maps. These maps provide a high-resolution pictorial representation of the topography on these outlet glaciers but are not used in our $\mathrm{d} / \mathrm{M} / \mathrm{d} t$ calculations.

The acceleration of Jakobshavn Isbræ (Joughin and others, 2008a) as the floating ice tongue thinned and broke away during 1996-2004 certainly contributes to this increased rate of mass loss. However, the near-linear change in $h(t)$ over 4 years, as shown in Figure $3 \mathrm{c}$ at six locations on Jakobshavn, suggests that the rate of thinning changed little during 2003-07. The rate of glacier thinning along the flowline (Fig. 14) shows a marked break at the EL (1440 m), 

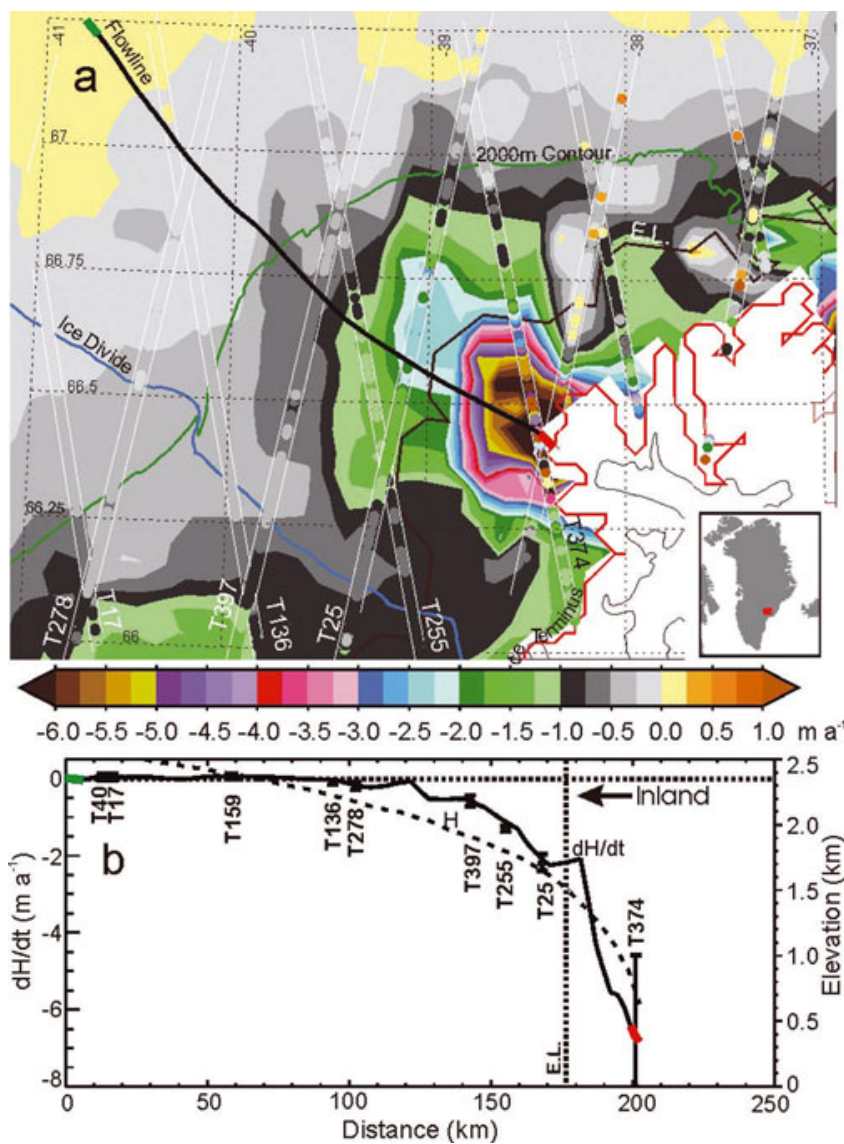

Fig. 15. (a) $\mathrm{d} H / \mathrm{d} t$ map of Helheimgletscher kriged on a $5 \mathrm{~km}$ grid from along-track $\mathrm{d} h / \mathrm{d} t$ plotted on the tracks. (b) $\mathrm{d} H / \mathrm{d} t$ profile (interpolated from $\mathrm{d} H / \mathrm{d} t$ map) and $H$ profile along a central flowline (black curve in (a)). Black symbols are $\mathrm{d} h / \mathrm{d} t \pm \sigma_{\mathrm{d} h / \mathrm{d} t}$ at points where the flowline crosses the ICESat tracks. Red and green segments in (a) indicate the ends of flowline.

with increasingly larger rates of thinning at lower elevations downstream of the EL (slope of $1.08 \mathrm{~m} \mathrm{a}^{-1}(100 \mathrm{~m})^{-1}$. Above the EL the slope of the thinning rate is $0.38 \mathrm{~m} \mathrm{a}^{-1}(100 \mathrm{~m})^{-1}$, or only one-third of that below the EL. Because the location of the EL is determined by the surface mass balance, and not by ice dynamics, this change at the EL cannot be explained by a change in the rate of dynamic thinning at this location. Assuming that the thinning above the EL is all caused by ice dynamics, extension of the $0.38 \mathrm{~m} \mathrm{a}^{-1}\left(100 \mathrm{~m}^{-1}\right.$ thinning rate to below the EL suggests that at $1000 \mathrm{~m}$ elevation, for example, about half of the $\sim 6 \mathrm{ma}^{-1}$ thinning is from dynamics and the other half is from increased melting. Therefore, increased melting and flow acceleration appear to be contributing similar amounts to the current thinning on the lower part of the glacier. Similarly, Helheimgletscher on the east coast also shows a break in the thinning rate near the EL (Fig. 15).

Two northern glaciers with floating ice tongues are Petermann Gletscher in the northeast corner of DS1.1 (Fig. 16) and Hagen Bræ in the northeast corner of DS1.3 (Fig. 17). $\mathrm{d} H / \mathrm{d} t$ on the floating part of Petermann shows an oscillating mixture of thickening and thinning, with an average close to zero, thinning inland of the grounding line to $\sim 1400 \mathrm{~m}$, and thickening at higher elevations (Figs 16 and 4c). The pattern of $d H / d t$ on Hagen Bræ is thickening on the floating part, strong thinning to about $600 \mathrm{~m}$, and thickening inland to $\sim 1000 \mathrm{~m}$. This pattern of thinning of grounded ice

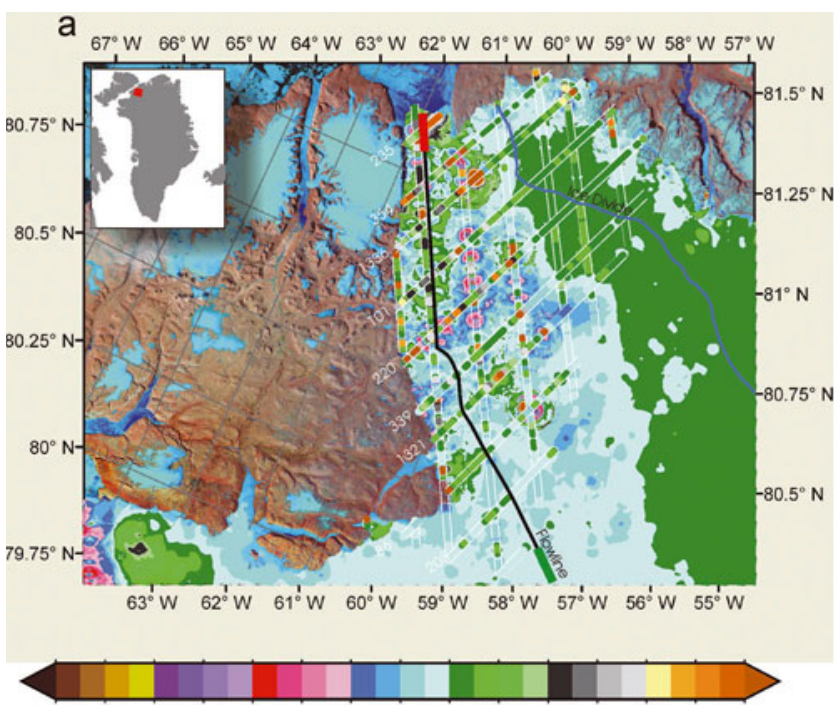

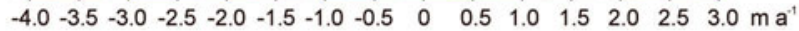

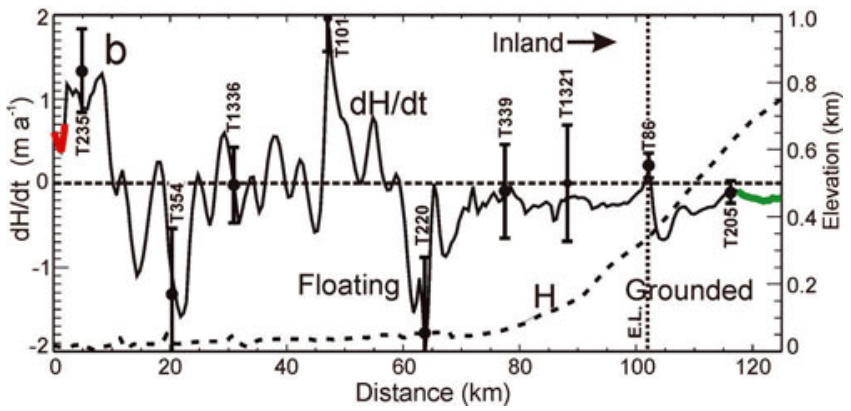

Fig. 16. (a) $\mathrm{d} H / \mathrm{d} t$ map of Petermann Gletscher kriged on a $500 \mathrm{~m}$ grid from along-track $\mathrm{d} h / \mathrm{d} t$ plotted on the tracks. (b) $\mathrm{d} H / \mathrm{d} t$ profile (interpolated from $\mathrm{d} H / \mathrm{d} t$ map) and $H$ profile along a central flowline (black curve in (a)). Black symbols are $\mathrm{d} h / \mathrm{d} t \pm \sigma_{\mathrm{d} h / \mathrm{d} t}$ at points where the flowline crosses the ICESat tracks. Red and green segments in (a) indicate the ends of flowline.

inland of ice tongues that are not significantly thinning suggests that factors other than a decrease in the buttressing effect (Thomas and others, 2004) of floating ice are affecting the thinning of the grounded ice on these glaciers.

\subsection{Dynamic thinning and inland coupling}

The increase in $\mathrm{d} H_{\mathrm{bd}} / \mathrm{d} t$ in 2003-07 compared with 19922002 (Fig. 10) is large below the EL $\left(-19\right.$ to $\left.-72 \mathrm{~cm} \mathrm{a}^{-1}\right)$, where it is a combination of local ablation changes and dynamic thinning (Pritchard and others, 2009). Above the $\mathrm{EL}$, the dynamic thinning $\left(\mathrm{d} H_{\mathrm{d}} / \mathrm{d} t\right)$ decreases with increasing elevation and becomes zero or slightly positive above $\sim 2300 \mathrm{~m}$ in averages over the GIS (Fig. 10e). The marked increase in dynamic thinning in 2003-07 extends into the GIS interior, decreasing with elevation $\left(-6\right.$ to $-30 \mathrm{~cm} \mathrm{a}^{-1}$ between 1200 and $1700 \mathrm{~m}$ and 5 to $1 \mathrm{~cm} \mathrm{a}^{-1}$ above $2700 \mathrm{~m}$ ).

The increase in dynamic thinning during the later period indicates that the effects of increased melting and accelerating glaciers, which are occurring at the margins, are dynamically extending inland to the highest elevations in some drainage systems. The increased thinning rate between 1500 and $2000 \mathrm{~m}$, for example, cannot be significantly affected dynamically by local changes in the surface mass balance, because the resulting changes in driving stresses from $A(t)$ are small. Also, this inland extension occurs relatively fast (decadal-scale response). 


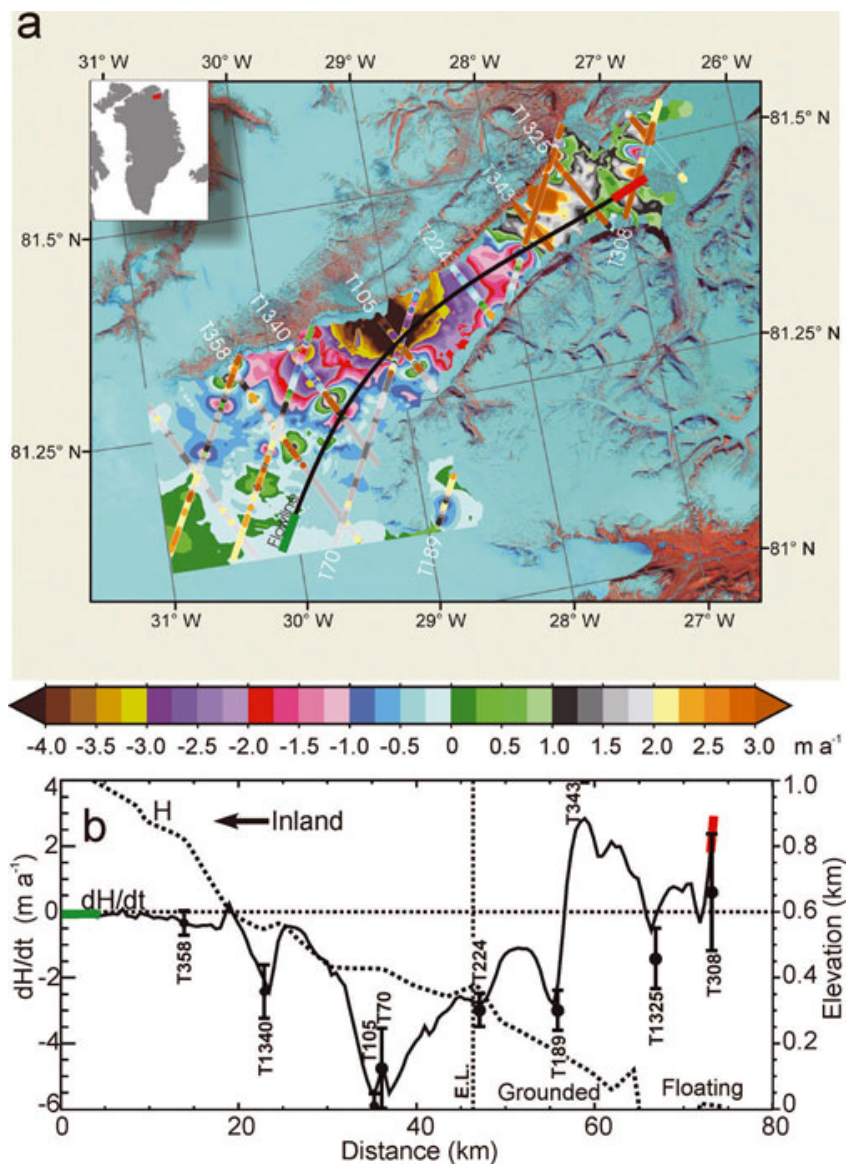

Fig. 17. (a) $\mathrm{d} H / \mathrm{d} t$ map of Hagen Bræ kriged on a $500 \mathrm{~m}$ grid from along-track $\mathrm{d} h / \mathrm{d} t$ plotted on the tracks. (b) $\mathrm{d} H / \mathrm{d} t$ profile (interpolated from $\mathrm{d} H / \mathrm{d} t$ map) and $H$ profile along a central flowline (black curve in (a)). Black symbols are $\mathrm{d} h / \mathrm{d} t \pm \sigma_{\mathrm{d} h / \mathrm{d} t}$ at points where the flowline crosses the ICESat tracks. Red and green segments in (a) indicate the ends of flowline.

However, the inland extension of dynamic thinning is not the same in all drainage systems. The largest changes and inland extension are in DS4 in the southeast, followed by DS7, DS3, DS5, DS6 and DS8 (as shown by $\mathrm{d} M_{\mathrm{bd}} / \mathrm{d} t$ in Fig. 12). The response time for inland dynamic coupling should be fastest in DS4 (as observed; Fig. 12) where the ice is warmer and deforms more easily and where the slopes are steep and the distance from the margin to the ice divide is smaller, i.e. $100-200 \mathrm{~km}$. In contrast, $\mathrm{d} H_{\mathrm{bd}} / \mathrm{d} t$ is nearly the same in both time periods in DS1 and DS2 in the north, where the ice is colder and the slopes are less steep.

\subsection{Response to climate change}

Changes in $A(t)$ and $T(t)$ on the GIS have immediate effects on the surface mass balance, the surface elevation and ice thickness, $D$, and the surface slope, $\alpha$. Changes in $D$ and $\alpha$ also change the driving stresses that force the ice flow, but these changes are generally expected to affect the ice dynamics only on timescales of centuries (Huybrechts and de Wolde, 1999). Two mechanisms for rapid response of the ice dynamics to climate that have been observed in Greenland are changes in buttressing of outlet glaciers caused by removal of their floating ice tongues (Thomas and others, 2004; Nick and others, 2009) and changes in basal lubrication and sliding from the melt/acceleration effect (Zwally and others, 2002b; Joughin and others, 2008b; Van de Wal and others, 2008; Bartholomew and others, 2010).
The observed increase of $164 \mathrm{Gt} \mathrm{a}^{-1}$ in $\mathrm{d} / \mathrm{M} / \mathrm{d} t$ to $171 \mathrm{Gt} \mathrm{a}^{-1}$ suggests that the GIS is responding to enhanced climate warming in the Arctic (AMAP, 2009), and that massexchange processes and ice dynamics causing greater mass loss are dominating those of mass gain. The thinning at the margins and thickening inland during the 1990s was already consistent with a response to a warmer climate, even though the mass balance then was close to zero. From 1997 to 2007, the 10 year trend in our AVHRR temperature record is $+1.7 \mathrm{~K}(10 \mathrm{a})^{-1}$, which compares with a $2.7 \mathrm{~K}(10 \mathrm{a})^{-1}$ increase (Hall and others, 2008) for 2000-06 and a $1.8 \mathrm{~K}(10 \mathrm{a})^{-1}$ increase (Box and others, 2009) for 1994-2007. Our corresponding increase in $A(T(t))$ is $8.5 \%(10 \mathrm{a})^{-1}$, which compares with $7 \%(10 a)^{-1}$ for $1988-2004$ and $3.3 \%(10 a)^{-1}$ for $1958-$ 2003 from regional-climate surface mass-balance models (Hanna and others, 2005; Box and others, 2006).

The increased mass loss is partly due to changes in surface mass balance and partly to changes in the ice dynamics. Since temperature increase is the primary forcing for these changes, including the variation of $A(t)$ with $T(t)$, it might be expected that an additional warming of $3.4 \mathrm{~K}$ in another two decades would increase the rate of loss to $500 \mathrm{Gta}^{-1}$ (1.4 $\mathrm{mm} \mathrm{a}^{-1}$ sea-level rise), assuming a linear relationship between temperature increase and mass loss. Numerical models of ice-sheet response to climate change in the next century generally account for changes in surface mass balance, but either neglect the effects of surface changes on the ice dynamics or only consider local changes in the driving forces. Most models do not include higherorder stress couplings within the ice, melt/acceleration effects, or the acceleration of outlet glaciers. The observed increase in dynamic thinning in 2003-07 and the dynamic coupling inland on decadal timescales is a new indication of how the GIS is responding to climate change that needs to be accounted for in predicting ice-sheet behavior.

\section{SUMMARY}

The mass changes of the GIS that we derive for two periods (1992-2002 and 2003-07) show a significant increase in the rate of mass loss (from $7 \pm 3 \mathrm{Gta}^{-1}$ to $171 \pm 4 \mathrm{Gta}^{-1}$ ) during a period of significant climate warming in Greenland $\left(\sim 2 \mathrm{~K}(10 \mathrm{a})^{-1}\right)$. From 1992-2002 to 2003-07, the contribution of the GIS to sea-level rise changed from essentially zero to $0.5 \mathrm{~mm} \mathrm{a}^{-1}, \sim 15 \%$ of the recent rate of sea-level rise (Solomon and others, 2007). Even though the GIS was close to mass balance during the 1990s, it was already showing characteristics of responding to a warmer climate, specifically thinning at the margins and thickening inland at higher elevations. Our results show that increased ice thinning due to increases in melting and acceleration of outlet glaciers during 2003-07 now strongly exceeds the inland thickening from increases in accumulation. Over the entire GIS, the mass loss between the two periods, from increased melting and ice dynamics, increased from 17 to $206 \mathrm{Gta}^{-1}$ while the mass gain, from increased precipitation and accumulation, increased from 10 to $25 \mathrm{Gta}^{-1}$. These results provide new quantitative information on how the competing mass-exchange processes that affect icesheet growth or shrinkage evolve with time in a changing climate. Understanding this evolution is important for the future, because the climate affecting the Greenland and Antarctic ice sheets is predicted to continue warming as the build-up of $\mathrm{CO}_{2}$ and other greenhouse gases in the Earth's 
atmosphere continues at an increasing rate (Solomon and others, 2007).

Our separation of the mass changes, $\mathrm{d} M_{\mathrm{a}} / \mathrm{d} t$, driven by accumulation variability, from the changes, $\mathrm{d} M_{\mathrm{bd}} / \mathrm{d} t$, driven by changes in ablation and ice dynamics is enabled by a new formulation of the elevation changes as perturbations from steady state. This formulation, as applied to measurements over two time periods (1992-2002 and 2003-07) with midpoints separated by 8 years, also provides a new determination of the changes in the dynamic thickening or dynamic thinning, and how the changes at the margins are propagating inland on decadal timescales.

Our detailed distributions derived for $\mathrm{d}^{\mathrm{a}}{ }_{C A} / \mathrm{d} t$ and $\mathrm{d} H_{\mathrm{bd}} / \mathrm{d} t$ in Figure $7 \mathrm{a}$ and $\mathrm{b}$ and for $\mathrm{d} M_{\mathrm{a}} / \mathrm{d} t, \mathrm{~d} M_{\mathrm{bd}} / \mathrm{d} t$ and $\mathrm{d} M / \mathrm{d} t$ (as a function of elevation and by drainage system in Figure 12) show how these parameters vary significantly among the different climate regimes of the GIS. The eight drainage systems have significant differences in important parameters that affect the surface balance and ice dynamics, including surface temperature, accumulation rate, internal ice temperature, basal melting or freezing, number of outlet glaciers with or without floating ice tongues, and the length of the ice margin terminating on land versus ocean. For example, the northern DS1 and DS2 have lower temperatures, lower accumulation rates and smaller ablation zones than the more southerly systems. Also, the drainage systems on the west coast have wide ablation zones with low slopes, and most of DS5 and DS6 terminate on land, whereas the east central DS3, the southeast DS4 and the west central DS7 and DS8 have many outlet glaciers terminating in the ocean and some with floating ice tongues. Our results provide a new description of the behavior of the GIS in these differing climate and glaciological regimes and therefore an improved basis for testing models of the ice response to climate change.

\section{ACKNOWLEDGEMENTS}

This research was supported by NASA's ICESat Project Science funding. We thank two anonymous reviewers and the scientific editor, H.A. Fricker, for helpful suggestions and comments, and the European Space Agency for providing radar altimeter data from ERS-1 and -2. We also thank R. Alley for his suggestion of using a relationship between accumulation rate and temperature to model the effects of accumulation variations on firn compaction. We are also grateful to all the engineers, scientists, and managers who contributed so much to making ICESat a very successful, pioneering space mission.

\section{REFERENCES}

Abdalati, W. and 9 others. 2001. Outlet glacier and margin elevation changes: near-coastal thinning of the Greenland ice sheet. J. Geophys. Res., 106(D24), 33,729-33,742.

Alley, R.B., M.K. Spencer and S. Anandakrishnan. 2007. Ice-sheet mass balance: assessment, attribution and prognosis. Ann. Glaciol., 46, 1-7.

Arctic Monitoring and Assessment Programme (AMAP). 2009. Summary: the Greenland ice sheet in a changing climate: Snow, Water, Ice and Permafrost in the Arctic (SWIPA). Oslo, Arctic Monitoring and Assessment Programme.

Bartholomew, I., P. Nienow, D. Mair, A. Hubbard, M.A. King and A. Sole. 2010. Seasonal evolution of subglacial drainage and acceleration in a Greenland outlet glacier. Nature Geosci., 3(6), 408-411.
Box, J.E. and 8 others. 2006. Greenland ice sheet surface mass balance variability (1988-2004) from calibrated polar MM5 output. J. Climate, 19(12), 2783-2800.

Box, J.E., L. Yang, D.H. Bromwich and L.-S. Bai. 2009. Greenland ice sheet surface air temperature variability: 1840-2007. J. Climate, 22(14), 4029-4049.

Clausen, H.B., N.S. Gundestrup, S.J. Johnsen, R. Bindschadler and J. Zwally. 1988. Glaciological investigations in the Crête area, central Greenland: a search for a new deep-drilling site. Ann. Glaciol., 10, 10-15.

Comiso, J.C. 2003. Warming trends in the Arctic from clear satellite observations. J. Climate, 16(21), 3498-3510.

Davis, C.H., Y. Li, J.R. McConnell, M.M. Frey and E. Hanna. 2005. Snowfall-driven growth in East Antarctic ice sheet mitigates recent sea-level rise. Science, 308(5730), 1898-1901.

Hall, D.K., R.S. Williams, Jr, S.B. Luthcke and N.E. Digirolamo. 2008. Greenland ice sheet surface temperature, melt and mass loss: 2000-2006. J. Glaciol., 54(184), 81-93.

Hanna, E., P. Huybrechts, I. Janssens, J. Cappelen, K. Steffen and A. Stephens. 2005. Runoff and mass balance of the Greenland ice sheet: 1958-2003. J. Geophys. Res., 110(D13), D13108. (10.1029/2004JD005641.)

Hanna, E. and 8 others. 2008. Increased runoff from melt from the Greenland Ice Sheet: a response to global warming. J. Climate, 21(2), 331-341.

Helsen, M.M. and 7 others. 2008. Elevation changes in Antarctica mainly determined by accumulation variability. Science, 320(5883), 1626-1629.

Holland, D.M., R.H. Thomas, B. de Young, M.H. Ribergaard and B. Lyberth. 2008. Acceleration of Jakobshavn Isbræ triggered by warm subsurface ocean waters. Nature Geosci., 1(10), 659-664.

Huybrechts, P. 2002. Sea-level changes at the LGM from icedynamic reconstructions of the Greenland and Antarctic ice sheets during the glacial cycles. Quat. Sci. Rev., 21(1-3), 203-231.

Huybrechts, P. and J. de Wolde. 1999. The dynamic response of the Greenland and Antarctic ice sheets to multiple-century climatic warming. J. Climate, 12(8), 2169-2188.

Ivins, E.R., X. Wu, C.A. Raymond, C.F. Yoder and T.S. James. 2001. Temporal geoid of a rebounding Antarctica and potential measurement by the GRACE and GOCE satellites. In Sideris, M.G., ed. Gravity, Geoid and Geodynamics 2000: GGG2000 IAG International Symposium, 31 July-4 August 2000, Banff, Alberta, Canada,. Berlin, Springer, 361-366. (International Association of Geodesy Symposia 123.)

Johannessen, O.M., K. Khvorostovsky, M.W. Miles and L.P. Bobylev. 2005. Recent ice-sheet growth in the interior of Greenland. Science, 310(5750), 1013-1016.

Joughin, I. and 7 others. 2008a. Continued evolution of Jakobshavn Isbræ following its rapid speedup. J. Geophys. Res., 113(F4), F04006. (10.1029/2008JF001023.)

Joughin, I., S.B. Das, M.A. King, B.E. Smith, I.M. Howat and T. Moon. 2008b. Seasonal speedup along the western flank of the Greenland Ice Sheet. Science, 320(5877), 781-783.

Krabill, W.B. and 9 others. 2000. Greenland ice sheet: highelevation balance and peripheral thinning. Science, 289(5478), 428-430.

Li, J. and H.J. Zwally. In press. Modeling of firn compaction for estimating ice-sheet mass change from observed ice-sheet elevation change. Ann. Glaciol., 52(59).

Li, J., H.J. Zwally and J.C. Comiso. 2007. Ice-sheet elevation changes caused by variations of the firn compaction rate induced by satellite-observed temperature variations (19822003). Ann. Glaciol., 46, 8-13.

Luthcke, S.B. and 8 others. 2006. Recent Greenland ice mass loss by drainage system from satellite gravity observations. Science, 314(5803), 1286-1289.

Luthcke, S.B. and 6 others. 2009. Recent changes in the Earth's land ice from GRACE: methods, signals and error. [Abstr. H13G-02.] Eos, 90(52), Fall Meet. Suppl. 
Nick, F.M., A. Vieli, I.M. Howat and I. Joughin. 2009. Large-scale changes in Greenland outlet glacier dynamics triggered at the terminus. Nature Geosci., 2(2), 110-114.

Peltier, W.R. 2004. Global glacial isostatic adjustment and the surface of the ice-age Earth: the ICE-5G(VM2) model and GRACE. Annu. Rev. Earth Planet. Sci., 32, 111-149.

Pritchard, H.D., R.J. Arthern, D.G. Vaughan and L.A. Edwards. 2009. Extensive dynamic thinning on the margins of the Greenland and Antarctic ice sheets. Nature, 461(7266), 971-975.

Rignot, E. and P. Kanagaratnam. 2006. Changes in the velocity structure of the Greenland Ice Sheet. Science, 311(5673), 986-990.

Shepherd, A. and D. Wingham. 2007. Recent sea-level contributions of the Antarctic and Greenland ice sheets. Science, 315(5818), 1529-1532.

Solomon, S. and 7 others, eds. 2007. Climate change 2007: the physical science basis. Contribution of Working Group I to the Fourth Assessment Report of the Intergovernmental Panel on Climate Change. Cambridge, etc., Cambridge University Press.

Straneo, F. and 7 others. 2010. Rapid circulation of warm subtropical waters in a major glacial fjord in East Greenland. Nature Geosci., 3(33), 182-186.

Thomas, R.H., E.J. Rignot, K. Kanagaratnam, W.B. Krabill and G. Casassa. 2004. Force-perturbation analysis of Pine Island Glacier, Antarctica, suggests cause for recent acceleration. Ann. Glaciol., 39, 133-138.

Thomas, R., E. Frederick, W. Krabill, S. Manizade and C. Martin. 2006. Progressive increase in ice loss from Greenland. Geophys. Res. Lett., 33(10), L10503. (10.1029/2006GL026075.)

Thomas, R., E. Frederick, W. Krabill, S. Manizade and C. Martin. 2009. Recent changes on Greenland outlet glaciers. J. Glaciol., 55(189), 147-162.
Van de Wal, R.S.W. and 6 others. 2008. Large and rapid meltinduced velocity changes in the ablation zone of the Greenland Ice Sheet. Science, 321(5885), 111-113.

Wingham, D.J., A. Shepherd, A. Muir and G.J. Marshall. 2006. Mass balance of the Antarctic ice sheet. Philos. Trans. R. Soc. London, Ser. A, 364(1844), 1627-1635.

Wouters, B., D. Chambers and E.J.O. Schrama. 2008. GRACE observes small-scale mass loss in Greenland. Geophys. Res. Lett., 35(2), L20501. (10.1029/2008GL034816.)

Zwally, H.J. and M.B. Giovinetto. 1997. Areal distribution of the oxygen-isotope ratio in Greenland. Ann. Glaciol., 25, 208-213.

Zwally, H.J. and M.B. Giovinetto. 2001. Balance mass flux and ice velocity across the equilibrium line in drainage systems of Greenland. J. Geophys. Res., 106(D24), 33,717-33,728.

Zwally, H.J. and J. Li. 2002. Seasonal and interannual variations of firn densification and ice-sheet surface elevation at Greenland summit. J. Glaciol., 48(161), 199-207.

Zwally, H.J. and 15 others. 2002a. ICESat's laser measurements of polar ice, atmosphere, ocean and land. J. Geodyn., 34(3-4), 405-445.

Zwally, H.J., W. Abdalati, T. Herring, K. Larson, J. Saba and K. Steffen. 2002b. Surface melt-induced acceleration of Greenland ice-sheet flow. Science, 297(5579), 218-222.

Zwally, H.J. and 7 others. 2005. Mass changes of the Greenland and Antarctic ice sheets and shelves and contributions to sealevel rise: 1992-2002. J. Glaciol., 51(175), 509-527.

Zwally, H.J., D. Yi, R. Kwok and Y. Zhao. 2008. ICESat measurements of sea ice freeboard and estimates of sea ice thickness in the Weddell Sea. J. Geophys. Res., 113(C2), C02S15. (10.1029/ 2007JC004284.)

MS received 30 June 2010 and accepted in revised form 30 September 2010 